\section{U.S. DEPARTMENT OF ENERGY}

\section{Office of}

ENERGY EFFICIENCY \& RENEWABLE ENERGY

\title{
R\&D Opportunities for Membranes and Separation Technologies in Building Applications
}


(This page intentionally left blank) 


\section{Preface}

The Department of Energy's (DOE) Building Technology Office (BTO), a part of the Office of Energy Efficiency and Renewable Energy (EERE) engaged Navigant Consulting, Inc., (Navigant) to develop this report recommending research \& development $(R \& D)$ initiatives for the advancement of separations technologies.

The initiatives identified in this report are Navigant's recommendations to BTO for pursuing to achieve DOE's energy efficiency goals. Inclusion in this report does not guarantee funding; initiatives must be evaluated in the context of all potential activities that BTO could undertake to achieve their goals.

\section{Prepared for:}

U.S. Department of Energy

Office of Energy Efficiency and Renewable Energy

Buildings Technologies Office

\section{Prepared by:}

Navigant Consulting, Inc.

77 South Bedford Street, Suite 400

Burlington, MA 01803

William Goetzler

Matt Guernsey

Youssef Bargach 


\section{Acknowledgments}

We would like to thank the individuals who provided valuable input to this report, including:

\begin{tabular}{|c|c|}
\hline Name & Organization \\
\hline Omar Abdelaziz & Oak Ridge National Laboratory \\
\hline Bamdad Bahar & Xergy Inc. \\
\hline Steven Baker & Emerson Climate \\
\hline Daniel Betts & Be Power Tech, Inc. \\
\hline Uwe Beuscher & WL Gore \& Associates \\
\hline Brian Bischoff & Oak Ridge National Laboratory \\
\hline Antonio Bouza & US Department of Energy \\
\hline Mark Buelow & BASF \\
\hline Frederick Cogswell & United Technologies Research Center \\
\hline Panos Datskos & Oak Ridge National Laboratory \\
\hline Steven C. DeCaluwe & Colorado School of Mines \\
\hline Jason DeGraw & National Renewable Energy Laboratory \\
\hline Debra Deininger & Integrated Device Technology \\
\hline Chaiwat Engtrakul & National Renewable Energy Laboratory \\
\hline Michael Geocaris & US Department of Energy \\
\hline Chioke Harris & National Renewable Energy Laboratory \\
\hline Michael Hu & Oak Ridge National Laboratory \\
\hline Ryan Huizing & dPoint Technologies \\
\hline Roderick Jackson & Oak Ridge National Laboratory \\
\hline Brian Johnson & Dais Analytic Corporation \\
\hline Eric Kozubal & National Renewable Energy Laboratory \\
\hline Chuck Kutscher & National Renewable Energy Laboratory \\
\hline Jason Lustbader & National Renewable Energy Laboratory \\
\hline Peter Luttik & 7AC Technologies \\
\hline Jeffrey McCutcheon & University of Connecticut \\
\hline Saeed Moghaddam & University of Florida \\
\hline Sven Mumme & US Department of Energy \\
\hline John Pellegrino & University of Colorado \\
\hline Jim Peters & PPG Industries \\
\hline Sameer Rao & Massachusetts Institute of Technology \\
\hline Rob Tenent & National Renewable Energy Laboratory \\
\hline Ed Trudeau & Emerson Climate \\
\hline Jeffrey Urban & Lawrence Berkeley National Laboratory \\
\hline Michael Wofsey & US Department of Energy \\
\hline Jason Woods & National Renewable Energy Laboratory \\
\hline John Zhai & University of Colorado \\
\hline
\end{tabular}




\title{
List of Acronyms
}

\author{
A/C Air-Conditioning \\ ARS Absorption Refrigeration Systems \\ BTO Building Technologies Office (Department of Energy, part of EERE) \\ CFD Computational Fluid Dynamics \\ $\mathrm{CO} \quad$ Carbon Monoxide \\ $\mathrm{CO}_{2} \quad$ Carbon Dioxide \\ DOE Department of Energy \\ EERE DOE's Office of Energy Efficiency and Renewable Energy \\ ERV Energy Recovery Ventilation \\ EUI Energy Use Intensity \\ EUL Effective Useful Life \\ FMEA Failure Modes and Effects Analysis \\ GWP Global Warming Potential \\ HVAC Heating, Ventilation, and Air-Conditioning \\ IAQ Indoor Air Quality \\ MOF Metal Organic Framework \\ MYPPs Multiyear Program Plans \\ NREL National Renewable Energy Laboratory \\ PEM Proton Exchange Membrane \\ PRO Pressure Retardant Osmosis \\ R\&D Research and Development \\ TRL Technology Readiness Level \\ US United States \\ VOC Volatile Organic Compounds
}




\section{Executive Summary}

The U.S. Department of Energy's (DOE) Building Technologies Office (BTO) within the Office of Energy Efficiency and Renewable Energy (EERE) seeks to reduce building energy consumption by $30 \%$, relative to 2010 consumption levels, by 2030.

DOE retained Navigant Consulting Inc. (hereafter, "Navigant") to recommend innovative membrane and separation technologies that can assist BTO in achieving its 2030 goal. This report identifies research and development $(R \& D)$ initiatives across several building applications where further investigations could result in impactful savings.

One-on-one interviews, as well as an industry-stakeholder workshop hosted at the National Renewable Energy Laboratory (NREL), helped guide and inform the findings of this report. Key themes emerged from that outreach, including:

- Preference for membrane solutions over other separation technologies - the outputs of stakeholder outreach were heavily weighted towards membrane technologies with few non-membrane separation technologies getting attention. A review of the stakeholder list indicates that the makeup of this group may have been the driver for this preference; while outreach was conducted to stakeholders in other separation fields, membranes researched expressed the greatest interest in participating.

- HVAC applications - HVAC technologies received higher levels of attention than any other application. The high number of HVAC experts represented in the stakeholder group was a driving factor.

- Membrane refinements - Many different incremental membrane performance improvements were of interest to the stakeholder group; together they constitute a substantive research opportunity.

- Interdisciplinary teams - Stakeholders overwhelmingly agreed on the need for increased interdisciplinary contributions on research teams.

- Technological immaturity of module architectures - Stakeholders suggested that membrane module design is still in its infancy as different organizations explore many varying approaches.

- Non-energy benefits - Stakeholders generally showed a higher level of interest in separation technologies that also yield non-energy benefits, such as increased comfort, safer/healthier environments, or potable water.

Navigant aggregated and refined the findings from the stakeholder outreach and identified the top 10 initiatives for DOE to consider based on their potential impact, relevance to DOE's goals, the criticality of DOE's involvement in their development, and their level of interest amongst select stakeholders.

Table ES-1 lists these initiatives; they are discussed further in Section 3 of this report. 
Table ES-1: Top 10 R\&D Initiatives

\begin{tabular}{|c|c|}
\hline ID & Initiative/Activity \\
\hline 1 & Develop new cross-functional membrane platforms \\
\hline 2 & Develop solutions to reduce membrane failure and/or minimize membrane failure impacts \\
\hline 3 & $\begin{array}{l}\text { Establish standard performance metrics and test procedures for membranes and membrane- } \\
\text { system }\end{array}$ \\
\hline 4 & Assess existing membrane landscape and further develop materials to improve characteristics \\
\hline 5 & Evaluate performance of, and develop novel applications for, membrane-based sensors \\
\hline 6 & Increase scalability of membranes and membrane production methods \\
\hline 7 & $\begin{array}{l}\text { Develop improved methods for accounting for and reducing boundary layer impacts in membrane } \\
\text { module design }\end{array}$ \\
\hline 8 & Develop novel production methods for membranes and membrane systems \\
\hline 9 & $\begin{array}{l}\text { Develop improved bonding methods (including adhesives, fastener-based bonding, and } \\
\text { thermal/ultrasonic welding) }\end{array}$ \\
\hline 10 & Improve efficiency of building-scale and larger non-potable water processing \\
\hline
\end{tabular}

The following report further characterizes each of these initiatives, as well as the industry challenges they aim to resolve. Section 1 contains a comprehensive list of all initiatives identified during develop of this report. 


\section{Table of Contents}

1 Introduction

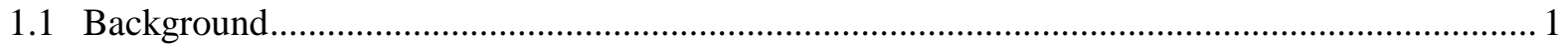

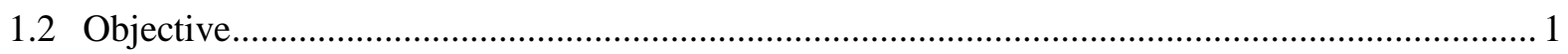

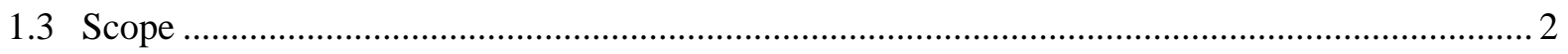

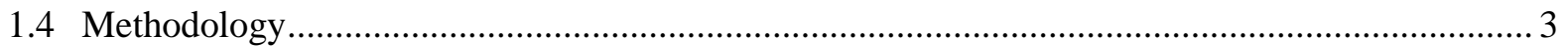

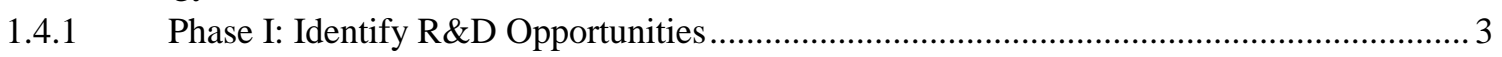

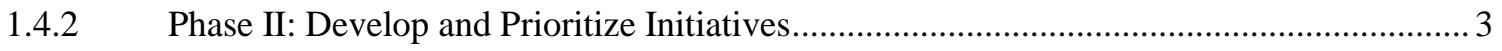

1.4.3 Phase III: Characterize Initiative Details ........................................................................ 5

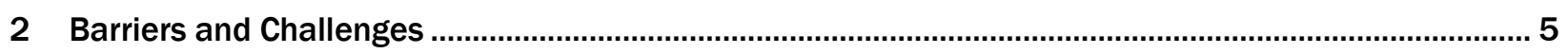

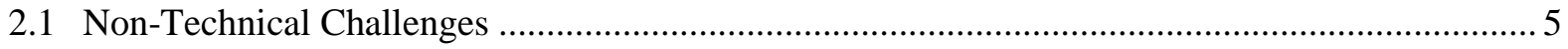

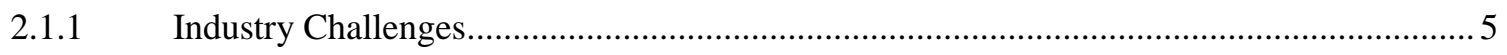

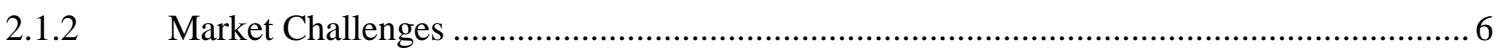

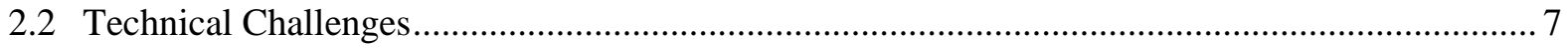

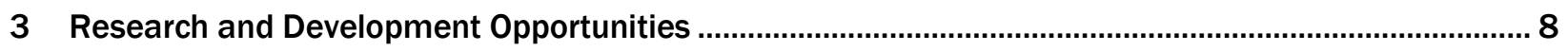

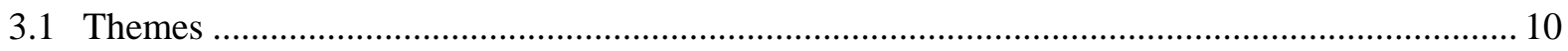

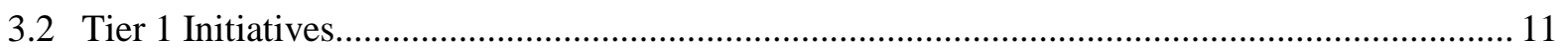

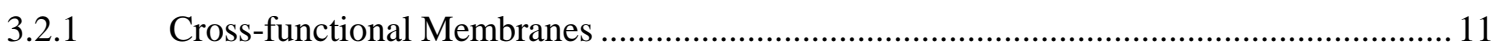

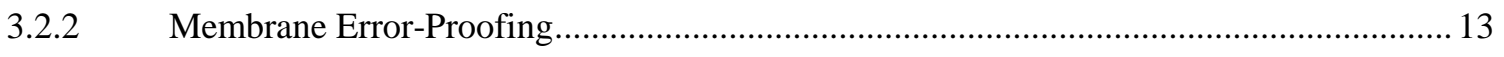

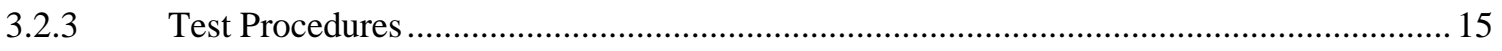

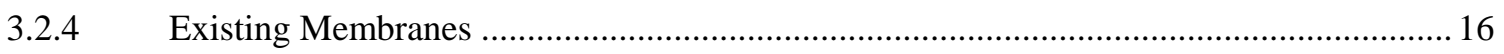

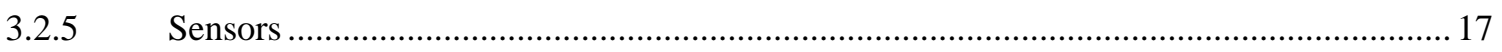

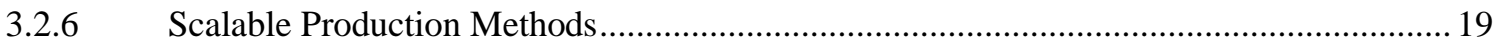

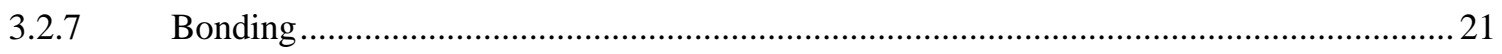

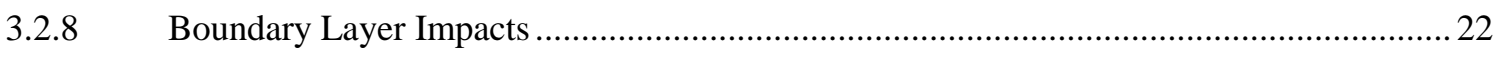

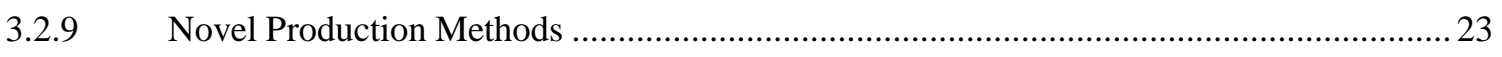

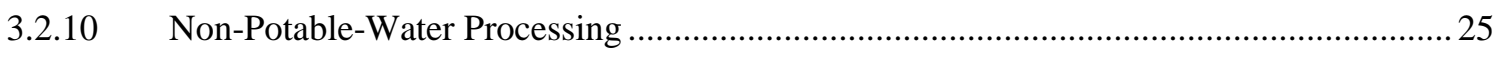

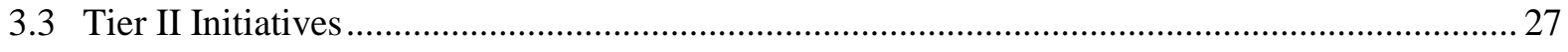

4 Appendix A: Building-System Membrane and Separation Technology Descriptions.............................29

5 Appendix B: US Department of Energy's Workshop on Separation Processes and Membrane

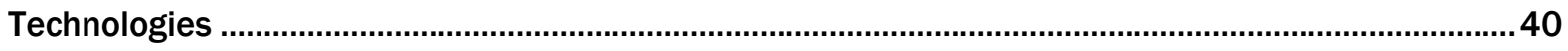

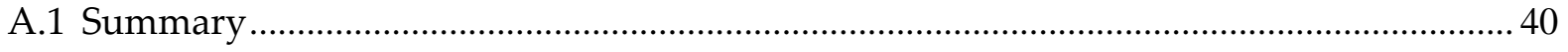

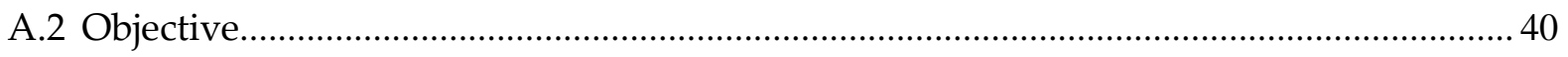

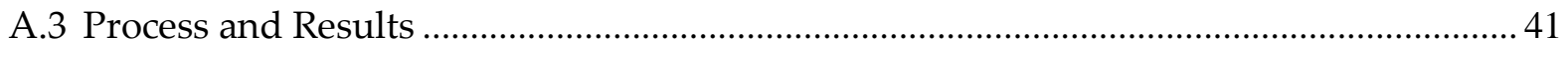

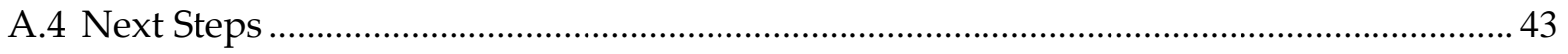

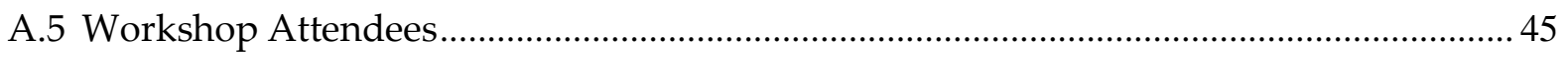

\section{List of Figures}

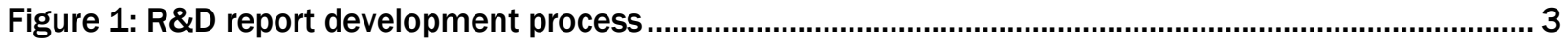


Figure 1: Building Systems Industry Analysis

Figure 1: [Appendix] 7AC Tech Membrane Cooling and Dehumidification ..................................................31

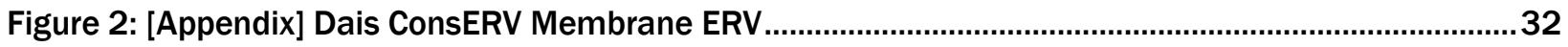

Figure 3: [Appendix] Membrane ERV and Power Generation ........................................................................... 33

Figure 4: [Appendix] Electrochemical Compressor ................................................................................... 34

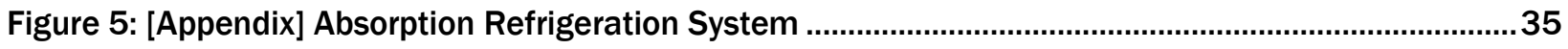

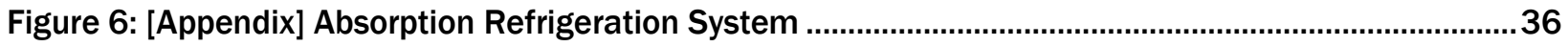

\section{List of Tables}

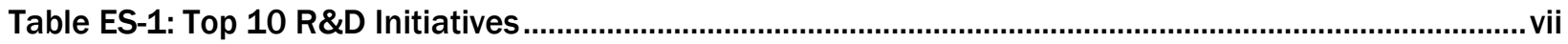

Table 1: Membrane and Separation Technology Applications ........................................................................ 2

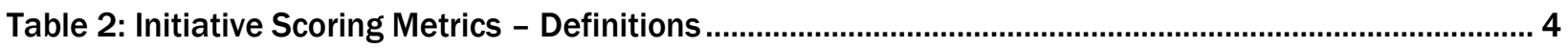

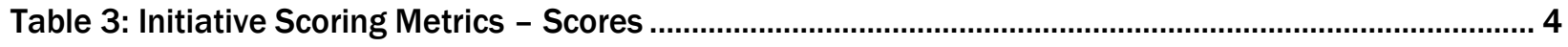

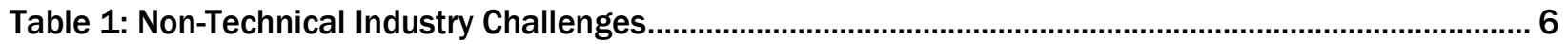

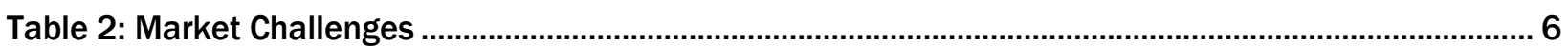

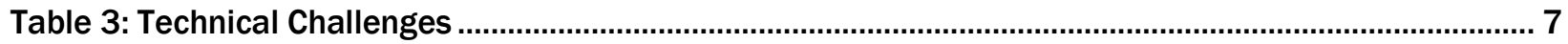

Table 1: R\&D Opportunities Summary - Tier I Initiatives ........................................................................... 9

Table 2: R\&D Opportunities Summary - Tier II Initiatives ................................................................................ 10

Table 3: Develop new cross-functional membrane platforms........................................................................12

Table 4: Develop solutions to reduce membrane failure and/or minimize membrane failure impacts...13

Table 5: Establish standardized performance metrics and test procedures for membranes and

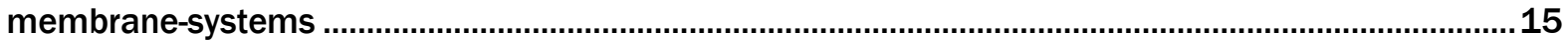

Table 6: Assess existing membrane landscape and further develop materials to improve characteristics

Table 7: Evaluate performance of, and develop novel applications for membrane-based sensors ..........18

Table 8: Develop more scalable membranes and membrane production methods ..................................19

Table 9: Develop improved bonding methods (including adhesives, fastener-based bonding, and thermal/ultrasonic welding)

Table 10: Develop improved methods for accounting for and reducing boundary layer impacts in membrane module designs

Table 11: Develop novel production methods for membranes and membrane systems 
Table 12: Improve efficiency of building-scale and larger non-potable-water processing........................25

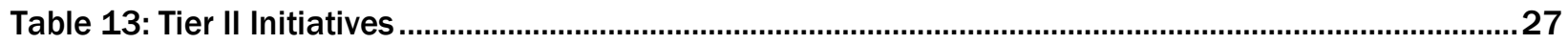

Table 1: [Appendix] Membrane Dehumidification Summary ................................................................29

Table 2: [Appendix] Membrane Humidification Summary................................................................................. 30

Table 3: [Appendix] Membrane Cooling and Dehumidification Summary ..................................................30

Table 4: [Appendix] Membrane ERV Summary

Table 5: [Appendix] Membrane ERV and Power Generation Summary .....................................................32

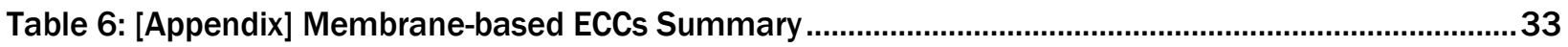

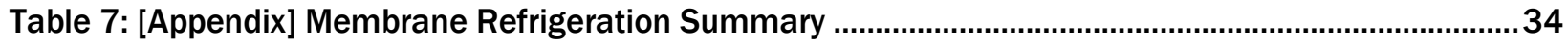

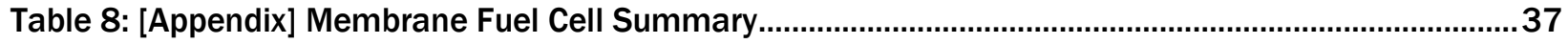

Table 9: [Appendix] Membrane Osmotic Power Summary ............................................................................... 37

Table 10: [Appendix] Membrane Moisture Control Summary ...............................................................38

Table 11: [Appendix] Membrane Clothes Dryer Summary …........................................................................... 38

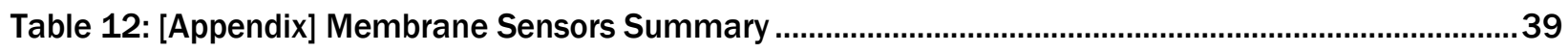

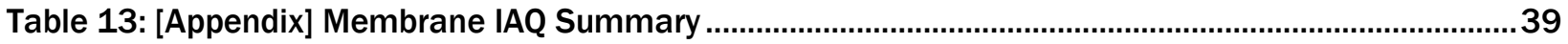




\section{Introduction}

\subsection{Background}

The United States Department of Energy's (US DOE) Building Technologies Office (BTO) has established in its Multi-Year Program Plan (MYPP)1 its strategy to reduce national building energy use intensity (EUI) by $30 \%$ compared to the 2010 levels by the year 2030 .

To meet the 2030 energy goals, BTO must support innovative solutions with significant energy savings potential. BTO seeks to develop next-generation technologies that dramatically improve efficiency and/or provide substantial cost reductions for existing high-efficient equipment.

As defined in its MYPP, BTO's mission is to:

Develop and promote efficient and affordable, environmentally friendly, technologies, systems, and practices for our nation's residential and commercial buildings that will foster economic prosperity, lower greenhouse gas emissions, and increase national energy security while providing the energy-related services and performance expected from our buildings.

DOE views membrane and separation technologies as part of an emerging field with significant room for growth that can help achieve the 2030 goals and further BTO's mission. DOE has previously funded membrane technologies but sees further opportunity to connect separation researchers with the building technologies community to further the applications for separation and membrane-based technologies in building systems.

\subsection{Objective}

With this report, BTO seeks to determine where the greatest opportunities for advancement in membrane and separation technologies exist, and to characterize those initiatives that are well suited to BTO support. This objective includes two elements:

1. Understand the landscape of membrane and separation technologies across various industries to determine how those technologies can be applied to BTO Emerging Technologies investment areas. BTO sought broad collaboration both inside and outside of BTO and thus, researched numerous technology areas, including:

- HVAC

- Appliances (e.g., dehumidifiers, refrigerators, etc.)

- Distributed generation (fuel cells)

- Building envelope

- Water efficiency

2. Characterize future BTO opportunities for membrane and separation research and development $(\mathrm{R} \& \mathrm{D})$

The characterization of the membrane and separations landscape, and the development of the initiatives described in this report, provide DOE with a wide array of paths to pursue in its efforts to meet the 2030 BTO goal. Each pathway is a focused topic with specific objectives, but is defined sufficiently broadly that potential BTO funding recipients can propose and compete on the merits of their own specific technology solutions.

${ }^{1}$ BTO Multi-Year Program Plan available at: https://energy.gov/sites/prod/files/2016/02/f29/BTO MYPP 2016.pdf 


\subsection{Scope}

Table 1 offers an overview of the applications of interest to DOE for this report. The list of end-uses is not exhaustive; their inclusion was the basis for research and information gathering. Further, DOE did not seek to cover this list of applications equally with new research opportunities, so the characterized initiatives in section 1 only cover those areas of specific interest among stakeholders.

The end-uses included here are indicative of BTO's vision to cast a broad net to enable development of technologies that may serve multiple uses in buildings and could benefit from collaborative DOE research, including with offices outside of BTO, like the Advanced Manufacturing Office.

Table 1: Membrane and Separation Technology Applications

\begin{tabular}{|c|c|c|}
\hline Category & End Use & Use-Case Example \\
\hline Appliances & $\begin{array}{l}\text { Refrigeration - Non- } \\
\text { Condensable Gas } \\
\text { Removal }\end{array}$ & $\begin{array}{l}\text { Removal of non-condensable gasses in compressors can boost } \\
\text { compressor performance }\end{array}$ \\
\hline Appliances & Clothes Dryer & $\begin{array}{l}\text { Removal of moisture from clothes-dryer exhaust, enabled by a water- } \\
\text { vapor-permeable membrane, reduces energy use through heat-recovery }\end{array}$ \\
\hline Appliances & $\begin{array}{l}\text { Flue-gas condensing } \\
\text { heat recovery }\end{array}$ & $\begin{array}{l}\text { A membrane to replace the condensing heat exchanger of condensing } \\
\text { natural gas equipment to eliminate the need for high-cost, acid- } \\
\text { resistant, stainless components. }\end{array}$ \\
\hline $\begin{array}{l}\text { Energy } \\
\text { Storage }\end{array}$ & Flow battery & $\begin{array}{l}\text { Improved electric generation/storage via a redox cell where an anolyte } \\
\text { and catholyte flow on opposite sides of a membrane to create current }\end{array}$ \\
\hline Envelope & $\begin{array}{l}\text { Multi-climate rain } \\
\text { screens }\end{array}$ & $\begin{array}{l}\text { Membrane-enabled moisture resistant barriers can protect a building } \\
\text { envelope from damage due to moisture }\end{array}$ \\
\hline HVAC & Space Cooling & $\begin{array}{l}\text { Separate sensible and latent heat controls can enable increased } \\
\text { efficiency and occupant comfort in buildings }\end{array}$ \\
\hline HVAC & $\begin{array}{l}\text { Electrochemical } \\
\text { compressors }\end{array}$ & $\begin{array}{l}\text { Leveraging hydrogen flow through a proton exchange membrane to } \\
\text { achieve compression }\end{array}$ \\
\hline HVAC & $\begin{array}{l}\text { Energy Recovery } \\
\text { Ventilation }\end{array}$ & $\begin{array}{l}\text { Vapor selective membrane for improved energy recovery relative to an } \\
\text { enthalpy wheel }\end{array}$ \\
\hline HVAC & Heat Pumps & $\begin{array}{l}\text { Membrane-enabled heat pump for combined sensible and latent } \\
\text { cooling }\end{array}$ \\
\hline HVAC & Humidity Control & $\begin{array}{l}\text { Moisture control can provide increased occupant comfort in space } \\
\text { heating applications }\end{array}$ \\
\hline HVAC & Indoor Air Quality & $\begin{array}{l}\text { Gas-separations for improved removal of VOCs and other harmful } \\
\text { gasses; membrane-enabled sensors to detect harmful gasses }\end{array}$ \\
\hline $\begin{array}{l}\text { Power } \\
\text { Generation }\end{array}$ & Ion Exchange & $\begin{array}{l}\text { Ion exchange membranes for reverse electro dialysis to generate } \\
\text { energy between water sources of different salinity }\end{array}$ \\
\hline $\begin{array}{l}\text { Power } \\
\text { Generation }\end{array}$ & Fuel Cells - PEM & $\begin{array}{l}\text { Improved power generation leveraging membrane separation of } \\
\text { protons from hydrogen atoms to create an electric current }\end{array}$ \\
\hline Sensors & VOC Identification & $\begin{array}{l}\text { More precise VOC-level identification can lead to safer buildings with } \\
\text { more efficient gas removal }\end{array}$ \\
\hline Water & Desalination & $\begin{array}{l}\text { Improved desalination processes to reduce energy use of desalination } \\
\text { facilities while providing an increasingly critical resource, fresh water }\end{array}$ \\
\hline
\end{tabular}




\begin{tabular}{|c|c|c|}
\hline Category & End Use & Use-Case Example \\
\hline Water & $\begin{array}{l}\text { Filtration, softening, } \\
\text { and purification }\end{array}$ & Separation of sediments and dissolved minerals from water sources \\
\hline Water & Wastewater recycling & $\begin{array}{l}\text { The large volumes of wastewater produced by buildings presents an } \\
\text { equally large opportunity for energy savings }\end{array}$ \\
\hline
\end{tabular}

\subsection{Methodology}

Figure 1 describes the process for developing this report.

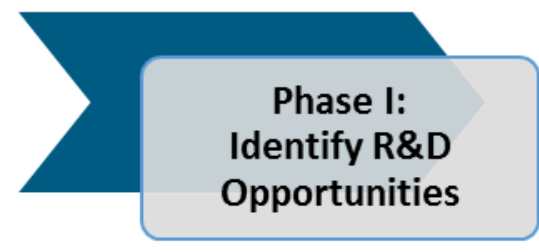

- Review existing solutions and tech status

- Research emerging technologies

- Gather stakeholder input

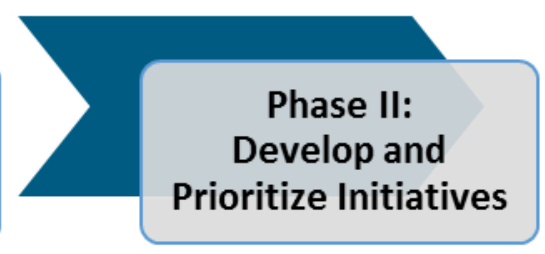

- Define initiatives

- Gather available data

- Prioritize initiatives

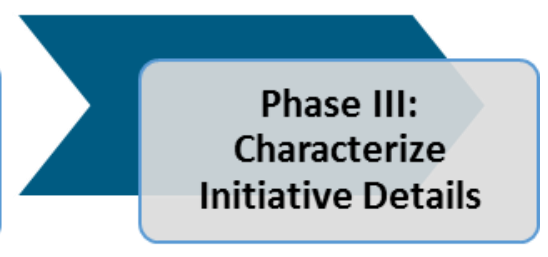

- Define initiative goals

- Explore additional details and approaches

- Identify stakeholder roles

Figure 1: R\&D report development process

The following subsections describe each project phase.

\subsubsection{Phase I: Identify R\&D Opportunities}

To identify potential membrane- and separations-related research opportunities, we conducted a technology scan of existing solutions. This research sought to uncover the overall industry trends, new emerging technologies, and barriers and challenges inhibiting adoption of these technologies. Phase I research sought to lay the groundwork for detailed initiative development.

To gather detailed inputs for initiatives, BTO hosted a stakeholder workshop.2 The workshop, held on June 8, 2017 at the National Renewable Energy Laboratory (NREL) in Golder, CO, sought to capture inputs on research and development (R\&D) needs and critical knowledge-gaps at the Technology Readiness Levels (TRL) TRL-2 and TRL-3. ${ }^{3}$

\subsubsection{Phase II: Develop and Prioritize Initiatives}

With the inputs from the foundational research and stakeholder workshop in Phase I, we developed a comprehensive list of R\&D ideas, which we refined into a preliminary initiative list. We refined the initiatives

\footnotetext{
${ }^{2}$ For more information on the outcomes of the workshop, refer to 5 - US Department of Energy's Workshop on Separation Processes and Membrane Technologies

${ }^{3}$ Details on Technology Readiness Levels (TRLs) can be found in the US DOE Technology Readiness Assessment, available at: https://energy.gov/sites/prod/files/em/Volume I/O SRP.pdf
} 
to develop a list that is both comprehensive and mutually exclusive. To develop such a list, we combined initiatives where there was overlap and added any initiatives discussed during the stakeholder workshop that were not incorporated in the original list of $\mathrm{R} \& \mathrm{D}$ ideas. The final score for any combined initiatives is the sum of the stakeholder votes from each of the initial individual initiatives.

We evaluated each initiative on four different metrics to prioritize the list and identify those that best fit DOE's needs. The prioritization process was as follows:

1. Score and rank the preliminary initiatives based on the metrics described in Table 2 .

2. Analyze and develop in more detail the top tier of initiatives (top 10)

Table 2: Initiative Scoring Metrics - Definitions

\begin{tabular}{|c|c|}
\hline Metric & Definition \\
\hline Impact & $\begin{array}{l}\text { Expected impact of the initiative in addressing a critical knowledge gap or overcoming a } \\
\text { key barrier to achieve significant energy savings in US buildings; savings may come } \\
\text { directly from efficiency improvements or through cost reductions for existing high- } \\
\text { efficiency technologies to increase adoption) }\end{array}$ \\
\hline $\begin{array}{l}\text { Fit with BTO } \\
\text { Mission }\end{array}$ & $\begin{array}{l}\text { Suitability of initiative (e.g., research stage and needs) to BTO's mission, }{ }^{4} \text { goals, and } \\
\text { capabilities (including the initiative's expected time to market) For example, high-risk, } \\
\text { disruptive R\&D is core to DOE's mission, while incremental, low-risk R\&D is not. BTO's } \\
\text { mission is also focused on supporting initiatives that are at TRL } 2 \text { or } 3 \text {. }\end{array}$ \\
\hline $\begin{array}{l}\text { Criticality of DOE } \\
\text { Involvement }\end{array}$ & Criticality of ВTO participation to the success of the initiative \\
\hline $\begin{array}{l}\text { Stakeholder } \\
\text { Interest }\end{array}$ & $\begin{array}{l}\text { Level of interest based on stakeholder comments and votes from the stakeholder } \\
\text { workshop. }\end{array}$ \\
\hline
\end{tabular}

Table 3 shows the scoring and weighting values associated with each of the above metrics.

Table 3: Initiative Scoring Metrics - Scores

\begin{tabular}{|c|c|c|c|c|c|c|}
\hline Metric & 5 & 4 & 3 & 2 & 1 & Weight \\
\hline Impact & Significant & $\begin{array}{l}\text { Semi- } \\
\text { Significant }\end{array}$ & Moderate & Modest & Minimal & $35 \%$ \\
\hline $\begin{array}{l}\text { Fit with BTO } \\
\text { Mission }\end{array}$ & $\begin{array}{l}\text { Core to } \\
\text { mission }\end{array}$ & $\begin{array}{l}\text { Semi-core to } \\
\text { mission }\end{array}$ & $\begin{array}{l}\text { Relevant to } \\
\text { mission }\end{array}$ & $\begin{array}{l}\text { Semi- } \\
\text { relevant to } \\
\text { mission }\end{array}$ & $\begin{array}{l}\text { Outside } \\
\text { scope / } \\
\text { mission }\end{array}$ & $35 \%$ \\
\hline $\begin{array}{l}\text { Criticality of DOE } \\
\text { Involvement }\end{array}$ & $\begin{array}{l}\text { Critical to } \\
\text { success }\end{array}$ & $\begin{array}{l}\text { Semi-critical } \\
\text { to success }\end{array}$ & $\begin{array}{l}\text { Beneficial to } \\
\text { success }\end{array}$ & $\begin{array}{l}\text { Semi- } \\
\text { beneficial to } \\
\text { success }\end{array}$ & $\begin{array}{l}\text { Unnecessary } \\
\text { for success }\end{array}$ & $15 \%$ \\
\hline $\begin{array}{l}\text { Stakeholder } \\
\text { Interest }^{5}\end{array}$ & $>20$ votes & $>15$ Votes & $>10$ votes & $>5$ votes & No Votes & $15 \%$ \\
\hline
\end{tabular}

Members from the project team independently scored each initiative based on the above, thereby resulting in a final list of initiatives, sorted by score.

\footnotetext{
${ }^{4}$ We considered initiatives not directly in BTO's purview but still relevant to DOE's mission as a fit with the mission. Additionally, initiatives with a broad idea related to BTO but specific functions in the domain of other offices also scored as a fit with the mission.

${ }^{5}$ For overlapping or duplicative initiatives at the workshop that we later combined, we also combined vote counts.
} 


\subsubsection{Phase III: Characterize Initiative Details}

The process yielded a prioritized list of initiatives 19 initiatives. We selected the top 10 initiatives (scores greater than 3.1) as Tier I. For each of the Tier I initiatives, we further refined the objectives of the initiative, outlined the potential impact on existing technical and market barriers, and recognized key stakeholder roles and responsibilities in pursuing the initiative.

Section 3 describes each of the detailed initiatives.

\section{Barriers and Challenges}

The industry faces numerous challenges, both technical and non-technical, surrounding the design, development, and adoption of membrane and separation technologies.

\subsection{Non-Technical Challenges}

\subsubsection{Industry Challenges}

Figure 1 shows the building systems industry landscape into which DOE is attempting to stimulate membrane and separation technology adoptions.
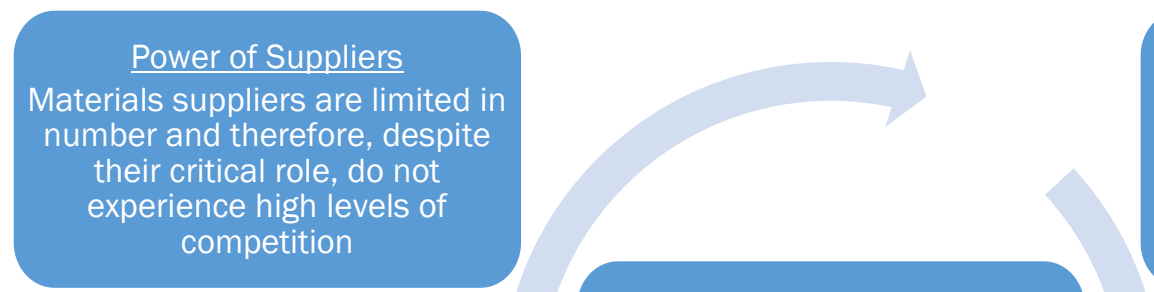

Threat of New Entrants

New entrants present little threat

in the building industry given the

name recognition and capital

expenditures necessary to gain market share

Industry Rivalry

Building systems industries

(particularly HVAC) are dominated

by a few key players that set the

standard for equipment adoption

Threat of Substitutions

Given the maturity of most

products in the buildings industry,

substitute products face

significant hurdles to widespread adoption
Power of Buyers

Customers have access to proven or relatively inexpensive existing solutions as compared to their membrane/separation-based system counterpart

Figure 1: Building Systems Industry Analysis 6

Table 1 provides further details on each of the industry forces described in Figure 1 and describes the impact each force exacts on the adoption of membrane and separation technologies.

\footnotetext{
${ }^{6}$ Industry analysis based loosely on Michael E. Porter's “The Five Competitive Forces that Shape Strategy;” Harvard Business Review, January 2008
} 
Table 1: Non-Technical Industry Challenges

\begin{tabular}{|c|c|c|}
\hline $\begin{array}{l}\text { Industry } \\
\text { Element }\end{array}$ & Challenge & Description \\
\hline Buyers & $\begin{array}{l}\text { High } \\
\text { bargaining } \\
\text { power }\end{array}$ & $\begin{array}{l}\text { Buyers have the option of inexpensive, proven, non-membrane and non- } \\
\text { separation-based equipment solutions; must provide a value proposition to } \\
\text { justify higher costs (incremental improvements are likely insufficient) }\end{array}$ \\
\hline Suppliers & $\begin{array}{l}\text { High cost of } \\
\text { supplier } \\
\text { materials }\end{array}$ & $\begin{array}{l}\text { Limited materials suppliers contribute to the high cost of membrane } \\
\text { materials }\end{array}$ \\
\hline Rivalry & $\begin{array}{l}\text { Competitive } \\
\text { industry } \\
\text { rivalry }\end{array}$ & $\begin{array}{l}\text { The industry for existing building systems is typically dominated by a few } \\
\text { key players in each end-use who have yet to adopt membrane and } \\
\text { separation technologies }\end{array}$ \\
\hline New entrants & $\begin{array}{l}\text { Limited } \\
\text { traction of } \\
\text { new entrants }\end{array}$ & $\begin{array}{l}\text { New entrants are at a disadvantage due to limited name recognition and } \\
\text { product awareness amongst both customers and service companies; } \\
\text { strategic partnerships or licensing to established players can help mitigate } \\
\text { this disadvantage }\end{array}$ \\
\hline $\begin{array}{l}\text { Substitution/ } \\
\text { Alternatives }\end{array}$ & $\begin{array}{l}\text { Limited need } \\
\text { for product } \\
\text { substitutes }\end{array}$ & $\begin{array}{l}\text { Substitute products must provide a value proposition to justify the increase } \\
\text { in system complexity or cost. For example, membrane-enabled HVAC } \\
\text { systems must compete with well-proven, reliable, DX technologies. }\end{array}$ \\
\hline
\end{tabular}

\subsubsection{Market Challenges}

Several market challenges exist that impede the adoption of membrane-based building technologies; Table 2 lists 13 of the biggest market challenges

Table 2: Market Challenges

\begin{tabular}{l|l}
$\begin{array}{l}\text { Challenge } \\
\text { Manufacturing scale- }\end{array}$ & $\begin{array}{l}\text { Building a customer base and enabling high-volume, low cost manufacturing is } \\
\text { challenging and may hinder technology deployment. Some end-uses, however, } \\
\text { such as building envelope might come to scale easier (due to higher demand, for } \\
\text { example). }\end{array}$ \\
\hline $\begin{array}{l}\text { Lack of uniform test } \\
\text { procedures \& metrics }\end{array}$ & $\begin{array}{l}\text { Industry lacks uniform testing standards and metrics by which they can } \\
\text { quantitatively evaluate and compare different membrane solutions }\end{array}$ \\
\hline $\begin{array}{l}\text { Lack of consumer } \\
\text { knowledge }\end{array}$ & $\begin{array}{l}\text { Given the novel nature of membrane and separation technologies, customer } \\
\text { confidence in these technologies is very low; testing is required to demonstrate } \\
\text { the reliability of products }\end{array}$ \\
\hline $\begin{array}{l}\text { Limited industry } \\
\text { collaboration to date }\end{array}$ & $\begin{array}{l}\text { Collaboration between researchers, industry, end users, system designers, and } \\
\text { manufacturers is low, leading to imperfect solutions. Researchers' focus is } \\
\text { primarily on developing the highest performing membranes rather than the } \\
\text { membranes most likely to be commercialized. }\end{array}$ \\
\hline $\begin{array}{l}\text { Lack of defined } \\
\text { performance targets }\end{array}$ & $\begin{array}{l}\text { Researchers and industry do not currently have clear performance targets for } \\
\text { their membrane/separation-based technologies, making research difficult to } \\
\text { guide and resulting in a wide range of solutions, many of which may be off target. }\end{array}$ \\
\hline
\end{tabular}


Challenge

Difficult to evaluate competing membrane solutions

Limited product awareness

Relatively long investor time horizon compared to other emerging techs

Poor economies of scope

Servicing that requires highly trained technicians and specialized parts

Costly environmental permitting required for manufacturing

Difficult to meet all conditions required for building integration

\section{Description}

Multiple solution pathways can exist when leveraging membranes to reach building-system performance targets. It is difficult to compare competing approaches without extensively designing or developing each one (e.g., two membranes with different selectivity and permeability could theoretically both serve the same purpose using different implementations).

Customer education in this field is relatively low; potential buyers are unfamiliar with the enabling technologies and unaware of product benefits

Traditional funding sources have proven difficult for many companies to secure in this field given the relatively early stage of research and high payback period relative to other emerging technologies

Companies operating in this space are still unable to benefit from economies of scope given limited product lines

Customers may have difficulty securing technicians for service calls due to: 1 .) lack of expertise on new products, or 2.) lack of reliable sources of parts from young manufacturers (or worst-case, a manufacturer that goes out of business).

Environmental permits required for membrane manufacturing can be costly and provide a challenge for younger companies with limited capital. These permits may apply even when manufacturers are only producing limited quantities in early stages of development, increasing R\&D costs.

Developing aesthetically pleasing, compact, and robust solutions is difficult to achieve but necessary in the buildings space (particularly for envelop and appliance applications)

\subsection{Technical Challenges}

Table 3 describes the most pressing technical barriers and challenges that must be addressed to enable substantive impact from membrane and separation technologies in building applications.

Table 3: Technical Challenges

\section{Challenge}

Low cross-

functionality of existing membranes

Limited effectiveness of bonding methods

High boundary layer resistances and impacts

\section{Description}

Membranes are typically developed with very specific functions in mind and are not often easily adapted to other applications

Methods for both membrane-to-membrane as well as membrane-to-component bonding need improvement, current methods can be costly, inconsistent, or not strong enough to withstand in-module operations.

Boundary layers directly adjacent to a membrane can have a significant negative impact on the membrane's performance; Little research is available documenting the change in membrane boundary-layer resistances when integrated into a module or on methods for reducing boundary-layer impacts when designing systems. 


\begin{tabular}{|c|c|}
\hline Challenge & Description \\
\hline $\begin{array}{l}\text { Cost/difficulty to } \\
\text { customize } \\
\text { membrane } \\
\text { properties }\end{array}$ & $\begin{array}{l}\text { Currently, specific membrane applications require specific customization of } \\
\text { membrane properties; solutions are either imperfect "off the shelf" products or } \\
\text { significantly tailored, costly, individually developed, membranes. }\end{array}$ \\
\hline $\begin{array}{l}\text { Limited means to } \\
\text { minimize membrane } \\
\text { compaction under } \\
\text { high pressures }\end{array}$ & $\begin{array}{l}\text { Pores under great pressure are prone to compress, thereby reducing permeability. } \\
\text { It is difficult to reduce instances of this type of failure without manipulating system } \\
\text { properties (e.g. flux or pressure gradient) that can compromise system } \\
\text { performance. }\end{array}$ \\
\hline $\begin{array}{l}\text { Difficulty of } \\
\text { preventing } \\
\text { membrane fouling }\end{array}$ & $\begin{array}{l}\text { Deposition of particles from the feed onto or into separation systems reduces } \\
\text { performance; includes biofouling. This can include slow build-up over time from } \\
\text { regular feeds or one-time deposits from improperly filtered feeds entering the } \\
\text { system }\end{array}$ \\
\hline $\begin{array}{l}\text { Difficulty of } \\
\text { minimizing instances } \\
\text { of pore collapse }\end{array}$ & $\begin{array}{l}\text { Pores, for many reasons, can collapse, causing a tear or defect in a membrane. It } \\
\text { is hard to predict where these collapses will occur, and therefore, how to mitigate } \\
\text { them. }\end{array}$ \\
\hline $\begin{array}{l}\text { Difficultly of } \\
\text { achieving both high } \\
\text { selectivity and high } \\
\text { permeability in a } \\
\text { membrane }\end{array}$ & $\begin{array}{l}\text { Typically, there is a trade-off between selectivity and permeability, wherein the } \\
\text { more selective a system, the less likely it is to allow for high rates of flow through } \\
\text { the system. }\end{array}$ \\
\hline $\begin{array}{l}\text { Lack of robust } \\
\text { solutions that can } \\
\text { withstand difficult } \\
\text { building integration }\end{array}$ & $\begin{array}{l}\text { Technologies must withstand difficult operating conditions for extended periods of } \\
\text { time to meet the Effective Useful Life (EUL) of building end uses without the need } \\
\text { for excessive service visits }\end{array}$ \\
\hline $\begin{array}{l}\text { Difficult to maintain } \\
\text { high flux without } \\
\text { driving operating } \\
\text { pressures up }\end{array}$ & $\begin{array}{l}\text { Pressure-driven separation technologies that require high pressure differentials } \\
\text { create taxing operating conditions that can result in higher instances of failure, } \\
\text { while ones operating in low pressure differentials struggle to maintain high rates of } \\
\text { flux }\end{array}$ \\
\hline $\begin{array}{l}\text { Insufficient modeling } \\
\text { tool capabilities }\end{array}$ & $\begin{array}{l}\text { Inadequate tools for the development of membrane systems leads to imperfect } \\
\text { systems and, therefore, subsequently performance degradations }\end{array}$ \\
\hline $\begin{array}{l}\text { Insufficient } \\
\text { production volumes }\end{array}$ & $\begin{array}{l}\text { Researchers cannot provide the materials square footage necessary for higher } \\
\text { rates of adoption in the building systems industry and its end use applications. }\end{array}$ \\
\hline $\begin{array}{l}\text { Cost due to limited } \\
\text { production scale }\end{array}$ & $\begin{array}{l}\text { Cost/square foot of separations materials (particularly advanced membranes) is } \\
\text { still too high due to limited production quantities }\end{array}$ \\
\hline $\begin{array}{l}\text { Difficulty of system } \\
\text { integration }\end{array}$ & $\begin{array}{l}\text { Many technical challenges arise when attempting to integrate a membrane } \\
\text { solution into a system or module }\end{array}$ \\
\hline
\end{tabular}

\section{Research and Development Opportunities}

This section summarizes the R\&D opportunities that we identified for DOE to pursue, based on the feedback gathered from industry-stakeholders. Each opportunity ties directly to one or more challenges from Section 2, above. 
To provide initiatives of the highest relevance to DOE, we revised any preliminary initiative ideas that were TRL 4 or higher to focus only on those elements of the initiatives that were at the TRL 2 or 3 level prior. As the "Fit with BTO Mission" metric relies on a TRL of 2 or 3, not taking this step would result in artificially low scores for initiatives that could be addressing critical barriers. As described in Table 3, initiative scores represent impact, fit with BTO mission, criticality of DOE involvement, and stakeholder interest. The scored initiatives list yielded a set of Tier I initiatives (the top-ten initiatives), as well as nine Tier II initiatives. The list of Tier I and Tier II initiatives are described in Table 1 and Table 2, respectively.

Table 1: R\&D Opportunities Summary - Tier I Initiatives

\begin{tabular}{|c|c|c|c|}
\hline ID & Category & Initiative Description & Score \\
\hline 1 & Imprc & Develop new cross-functional membrane platforms & 4.2 \\
\hline 2 & Impro & $\begin{array}{l}\text { Develop solutions to reduce membrane failure and/or minimize membrane } \\
\text { failure impacts }\end{array}$ & 3.7 \\
\hline 3 & & $\begin{array}{l}\text { Establish standard performance metrics and test procedures for membranes } \\
\text { and membrane-system }\end{array}$ & 3.4 \\
\hline 4 & Impr & $\begin{array}{l}\text { Assess existing membrane landscape and further develop materials to } \\
\text { improve characteristics }\end{array}$ & 3.4 \\
\hline 5 & 号 & $\begin{array}{l}\text { Evaluate performance of, and develop novel applications for, membrane- } \\
\text { based sensors }\end{array}$ & 3.4 \\
\hline 6 & Prod & Increase scalability of membranes and membrane production methods & 3.3 \\
\hline 7 & Improvement & $\begin{array}{l}\text { Develop improved bonding methods (including adhesives, fastener-based } \\
\text { bonding, and thermal/ultrasonic welding) }\end{array}$ & 3.1 \\
\hline 8 & Des & $\begin{array}{l}\text { Develop improved methods for accounting for and reducing boundary layer } \\
\text { impacts in membrane module design }\end{array}$ & 3.1 \\
\hline 9 & Production & Develop novel production methods for membranes and membrane systems & 3.1 \\
\hline 10 & $\begin{array}{c}\text { 吕吕 } \\
\text { Application }\end{array}$ & Improve efficiency of building-scale and larger non-potable water processing & 3.0 \\
\hline
\end{tabular}


Table 2: R\&D Opportunities Summary - Tier II Initiatives

\begin{tabular}{|c|c|c|c|}
\hline ID & Category & Initiative Description & Score \\
\hline 11 & Impro & Develop improved Metal Organic Frameworks (MOFs) & 2.9 \\
\hline 12 & Improvement & $\begin{array}{l}\text { Develop new ceramic membranes and adapt existing ceramic membranes } \\
\text { to building applications }\end{array}$ & 2.9 \\
\hline 13 & Improvement & Develop composite membranes & 2.7 \\
\hline 14 & $\begin{array}{c}\text { 吕官 } \\
\text { Application }\end{array}$ & Evaluate and improve upon performance of separation technologies & 2.6 \\
\hline 15 & Improvement & $\begin{array}{l}\text { Evaluate performance of various membrane form-factors and develop new } \\
\text { or improved solutions }\end{array}$ & 2.6 \\
\hline 16 & & Develop prescribed methodology for evaluating scale-up-feasibility & 2.6 \\
\hline 17 & Improvement & $\begin{array}{l}\text { Develop new hybrid materials and adapt existing hybrid materials to building } \\
\text { applications }\end{array}$ & 2.5 \\
\hline 18 & & Develop methods for conducting accelerated-lifecycle membrane studies & 2.5 \\
\hline 19 & Design & $\begin{array}{l}\text { Develop improved modeling tools specifically for membranes and } \\
\text { membrane systems }\end{array}$ & 2.3 \\
\hline
\end{tabular}

Section 3.2 offers a more in-depth analysis of the Tier I initiatives. Section 3.2 provides further details about the Tier II initiatives.

\subsection{Themes}

Membrane and separation technologies could be a critical component of BTO's plan to achieve a reduction of the national building EUI by 2030. Many of the analyzed technologies are cross-cutting across multiple functions, thereby offering potential savings for numerous building end-use applications. Through our outreach and research, we identified some key themes that will drive how DOE can best aid development of these technologies:

- Preference for membrane solutions over other separation technologies - Given the expertise and interests of the stakeholder group, there was a strong preference for membrane topics as compared to 
other separation topics. As such, we were unable to glean much information to develop a set of initiatives representative of the issues affecting non-membrane separation technologies specifically. There is, however, substantial crossover between the two topic areas, allowing for benefits to separations technologies from development of the membrane-related initiatives. A review of the stakeholder list indicates that the makeup of this group may have been the driver for this preference; while outreach was conducted to stakeholders in other separation fields, membranes researched expressed the greatest interest in participating.

- HVAC applications - HVAC technologies received higher levels of attention given the disproportionately high number of HVAC experts represented in the stakeholder group. Through our outreach efforts, we sought to inject a greater range of expertise, but interest in other building applications was substantially lower.

- Membrane refinements - Many different incremental membrane performance improvements were of interest to the stakeholder group. These refinement opportunities are captured by Initiative 4 (see Section 3.2.4), which we developed by grouping the discussed improvement opportunities from the workshop.

- Interdisciplinary teams - Stakeholders overwhelmingly agreed on the need for increased interdisciplinary participation on research teams. Improved communication between researchers, industry members, manufacturers, and end-use appliance experts can have a meaningful impact on the commercial viability of the technology.

- Technological immaturity of module architectures - Stakeholders suggested that in many ways, membrane module design is still technologically immature, with a variety of different approaches and concepts all being explored. Opportunities exist to refine designs to achieve optimal performance, cost, and product lifetime.

- Non-energy benefits - Stakeholders generally showed a higher level of interest in separation technologies that also yield non-energy benefits, such as increased comfort, safer/healthier environments, or fresh water. Capturing these benefits is valuable in enabling commercially viable solutions for a broad range of the market.

\subsection{Tier 1 Initiatives}

The following subsections each provide further description of the challenges, stakeholder roles, and key objectives of each of the Tier I initiatives.

\subsubsection{Cross-functional Membranes}

Table 3 shows the prioritization score, key stakeholders, barriers addressed, steps and outcomes for developing cross-functional membrane platforms. 
Table 3: Develop new cross-functional membrane platforms

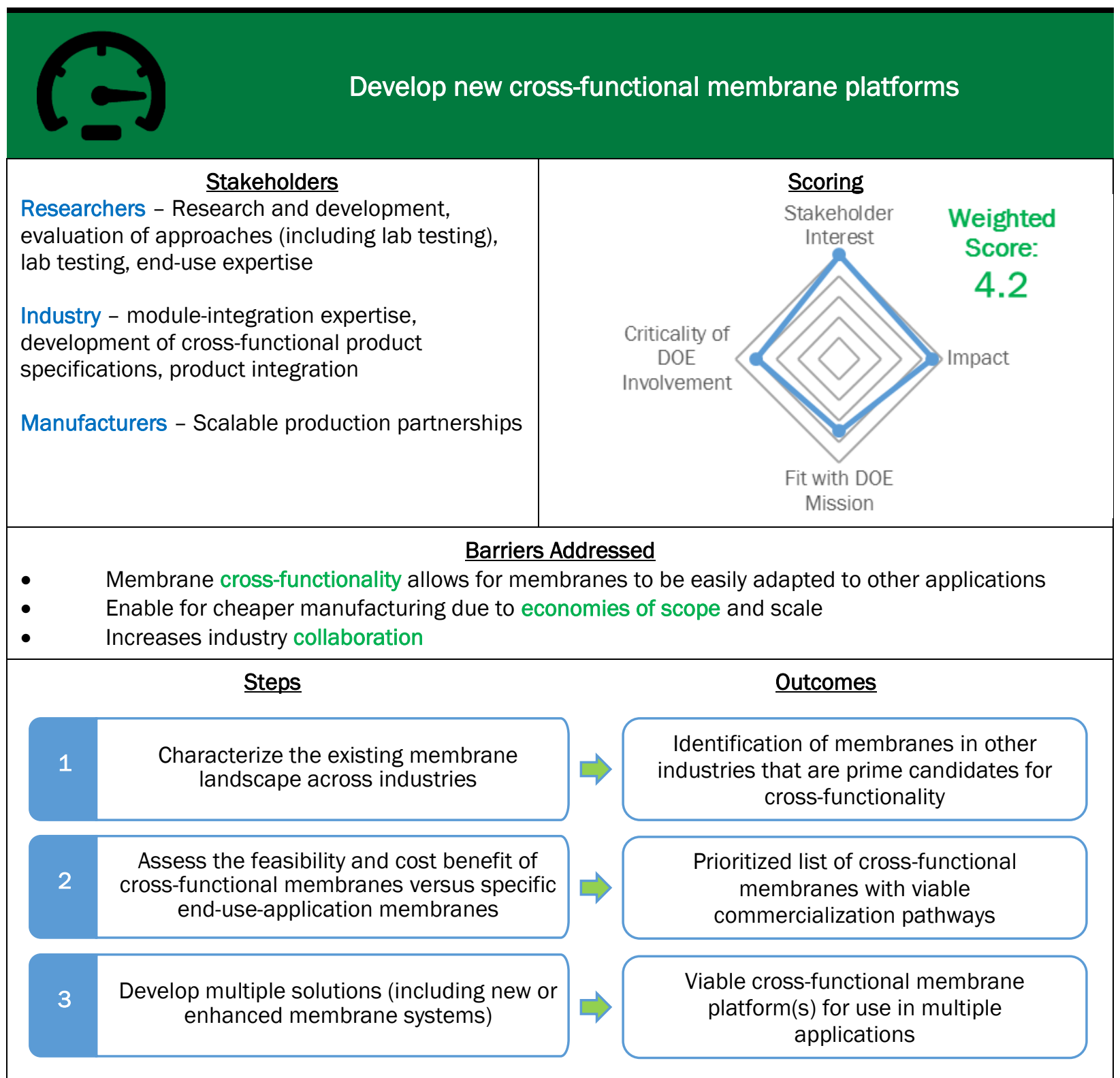

Membranes are often developed for and tailored to highly specific use cases. Such an approach to development limits membrane versatility. Cross-functional membrane platforms seek to bridge the gap between versatility and specificity. One embodiment of a cross-functional membrane platform is a consistent porous support layer onto which a variable transport layer can be grown to add more tailored functionality. Alternatively, as many building applications (particularly HVAC ones) require water vapor passive membranes, for example, a crossfunctional membrane would be a vapor passive membrane requiring only minimal changes (chemical or otherwise) to be effective across many of those applications.

Cross-functional membranes help address three key challenges limiting the success of membranes commercially. First, cross-functional membranes enable cheaper manufacturing due to economies of scope and scale. Second, they enable collaboration, as industry stakeholders are each working to improve the same membrane platform. Finally, developing cross-functional membranes can facilitate the use of membranes in 
new applications, given the reduced startup-time and cost achievable by increased economies of scope and scale.

DOE can assist in the development of cross-functional membranes by supporting:

- Development of deeper understanding of the characteristics of a suitable membrane platform, as well as what types of existing membranes are most suitable to be platforms or to be integrated with platforms and adapted to building end uses. To date, there has been a substantial amount of resources dedicated to the advancement of membranes, though much of the work has not considered crossfunctionality to be a high priority.

- Research to understand the tradeoffs between platforms and specialized membranes. In understanding the system impacts of utilizing a cross-functional (as opposed to custom) membrane, DOE can guide system engineers to understand the circumstances in which one approach is better than the other.

- Research to determine the chemical compatibility of cross-functional membranes. Such research could also provide a guide on end uses best suited to these types of membranes, but also on which chemical additives yield the highest performing derivative membranes from the membrane platform.

These research investigations can ultimately result in the development of membrane platforms, as well as generate insights into the best approach for the development of any future membrane platforms. Additionally, it provides industry with the opportunity for solution-driven innovations. In other words, membrane platform development can continue independent of specific applications. Consequently, emerging membrane applications can reach proof-of-concept with a smaller R\&D investment.

\subsubsection{Membrane Error-Proofing}

Table 4 shows the prioritization score, key stakeholders, barriers addressed, steps and outcomes for error proofing membranes.

Table 4: Develop solutions to reduce membrane failure and/or minimize membrane failure impacts

\begin{tabular}{|l|l|}
\multicolumn{2}{|c|}{ Develop solutions to reduce membrane failure and/or minimize } \\
membrane failure impacts \\
$\begin{array}{l}\text { Researchers - failure modes and effects analysis } \\
\text { (FMEA), testing to characterize failure } \\
\text { mechanisms, failure simulations, solution } \\
\text { development }\end{array}$ \\
$\begin{array}{l}\text { Industry - reliability specification development, } \\
\text { deployment and system integration of novel } \\
\text { solutions }\end{array}$ \\
$\begin{array}{l}\text { Error proofing can prevent or delay membrane failure, allowing for extended membrane life and, } \\
\text { therefore, reduced system life cost }\end{array}$ \\
\hline \multicolumn{2}{|c|}{ Barriers Addressed } \\
\hline
\end{tabular}




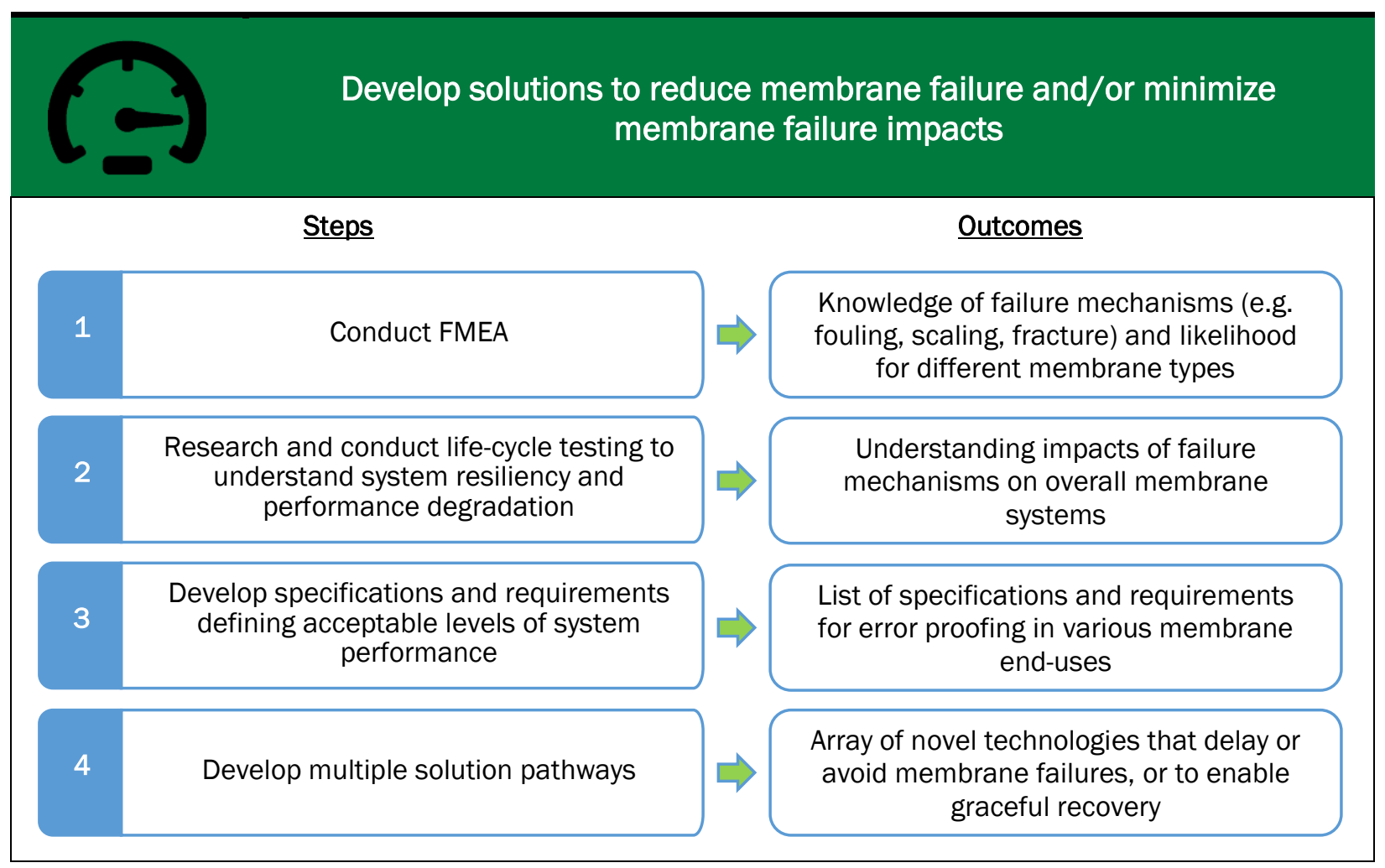

Membranes can succumb to several failure mechanisms that degrade the system's performance or render the membrane incapacitated, even under standard operating conditions. Solutions that delay or avoid membrane failure help to prolong product life and therefore market viability. Alternatively, membranes could also benefit from solutions that enable graceful recoveries following a membrane failure. The potential approach may change depending on the application and on the type of failure that the membrane may encounter.

To provide viable solutions, membrane researchers require a more comprehensive understanding of the failure mechanisms that occur in membranes. DOE can assist in developing this knowledge base by supporting research to characterize and evaluate failure modes in membranes. Potential research topics include but are not limited to:

- Measurement of membrane failure rates (including a broad range of failure modes), causes, and associated performance degradation

$\circ$ Understanding of the factors leading to higher rates of pore breakthrough

- Analysis of where pore collapse occurs and how to minimize collapse rates

- Exploration of methods to reduce the rate of membrane fouling and scaling

Potential solutions may include, but are not limited to:

- Self-healing membranes capable of fixing fractures or pore collapses

- Fouling resistant membranes

- Systems or methods that can control where fouling or scaling occurs

- In-situ reparability of membranes

- Self-cleaning membranes

- Error-proof membrane modules or packages (e.g., leak-proof hollow-fiber membrane modules) 


\subsubsection{Test Procedures}

Table 5 shows the prioritization score, key stakeholders, barriers addressed, steps and outcomes for developing standardized performance metrics and test procedures.

Table 5: Establish standardized performance metrics and test procedures for membranes and membrane-systems

\begin{tabular}{|l|l|}
\hline \multicolumn{2}{|c|}{ Establish standardized performance metrics and test procedures for membranes and } \\
Stakeholders \\
BTo - develop test procedures and standards, \\
verification of test results
\end{tabular}

Barriers Addressed

- Consistent membrane test procedures allow for uniform evaluation of membranes and membrane systems, resulting in more informed membrane selection for industry

\begin{tabular}{|c|c|c|c|}
\hline & Steps & Outcomes \\
\hline 1 & $\begin{array}{c}\text { Develop metrics for evaluating membrane and } \\
\text { membrane-system performance }\end{array}$ & $\begin{array}{c}\text { Consistent and relevant performance } \\
\text { metrics allowing for cross-manufacturer } \\
\text { membrane comparisons }\end{array}$ \\
\hline 2 & $\begin{array}{c}\text { Develop test procedures yielding the } \\
\text { previously developed metrics }\end{array}$ & $\begin{array}{c}\text { Quantitative evaluation of membrane and } \\
\text { membrane system performance }\end{array}$ \\
\hline
\end{tabular}

Current membrane-performance test procedures are limited in their capacity to characterize and evaluate the performance of existing membranes. One of the primary test procedures utilized by industry is the ASTM E96/E96M-10 Standard Test Method for Water Vapor Transmission of Materials; ${ }^{7}$ wherein the weight change of a dish with a fixed amount of distilled water, overlaid with a membrane, determines the rate of water-vaporflow through the membrane. While such tests are useful in estimating the vapor transmission rate through a membrane, they do not sufficiently quantify a membrane's overall performance in a real-world application or as part of a module. To integrate membranes into building applications, industry must have a method of uniformly evaluating such membrane properties as durability, selectivity, permeability, and rate of failure, among others.

\footnotetext{
${ }^{7}$ Source: http://www.astm.org/Standards/E96.htm
} 
DOE can assist in developing consistent metrics for evaluation of membrane properties and membrane performance (including the performance of membrane modules). DOE can then work closely with industry and researchers to develop consistent and accurate test procedures to quantify the metrics.

Such metrics give industry a reliable way to evaluate and catalogue the performance of different membranes, allowing for cross-manufacturer and cross-function comparisons of membrane solutions, which is a critical step in the design of building systems with integrated membrane components. Cataloguing the existing membrane stock and quantifying its performance relative to each of the defined metrics would allow system designers to focus more on system integration and less on membrane evaluation.

\subsubsection{Existing Membranes}

Table 6 shows the prioritization score, key stakeholders, barriers addressed, steps and outcomes for improving existing membranes.

Table 6: Assess existing membrane landscape and further develop materials to improve characteristics

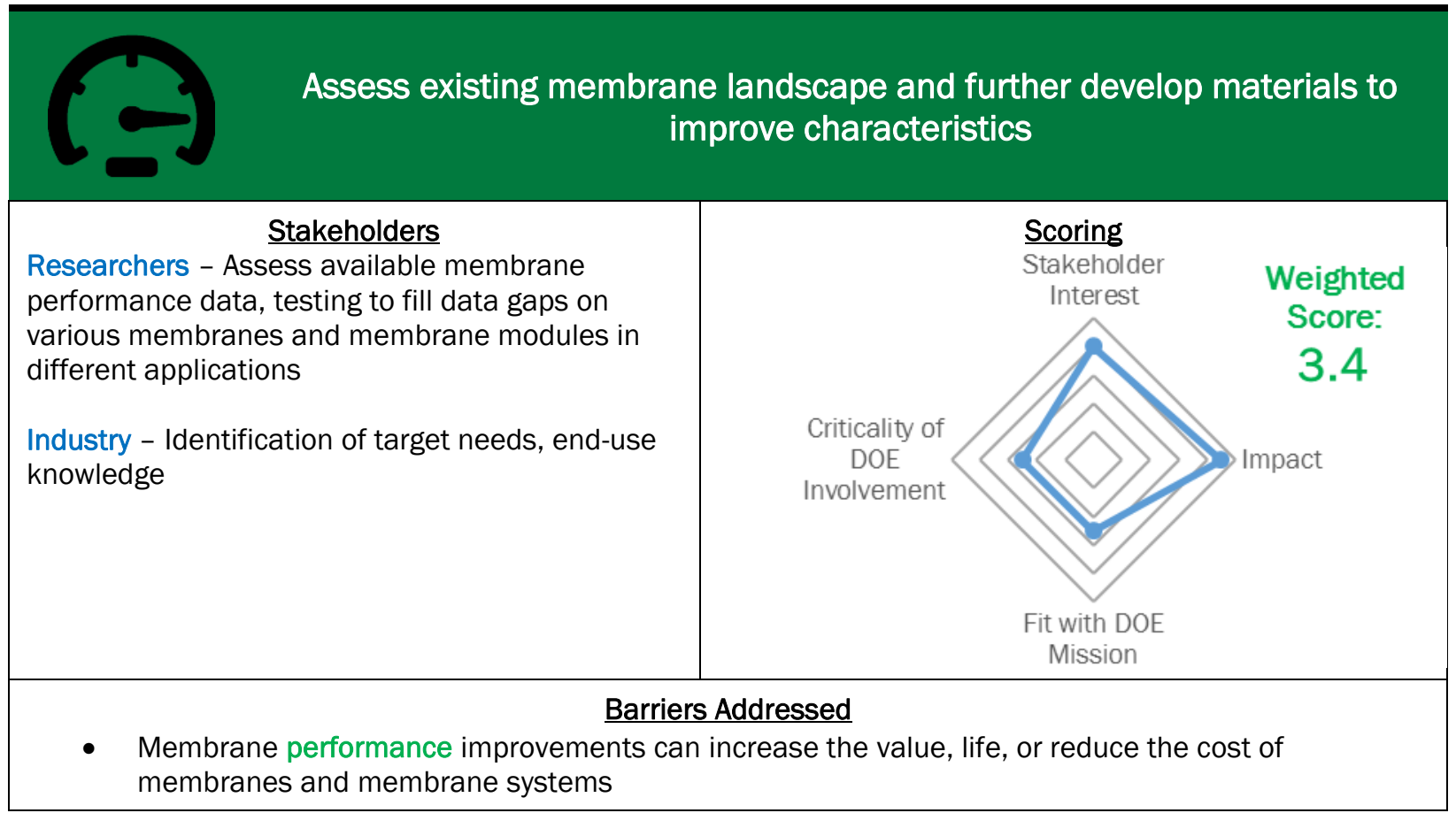




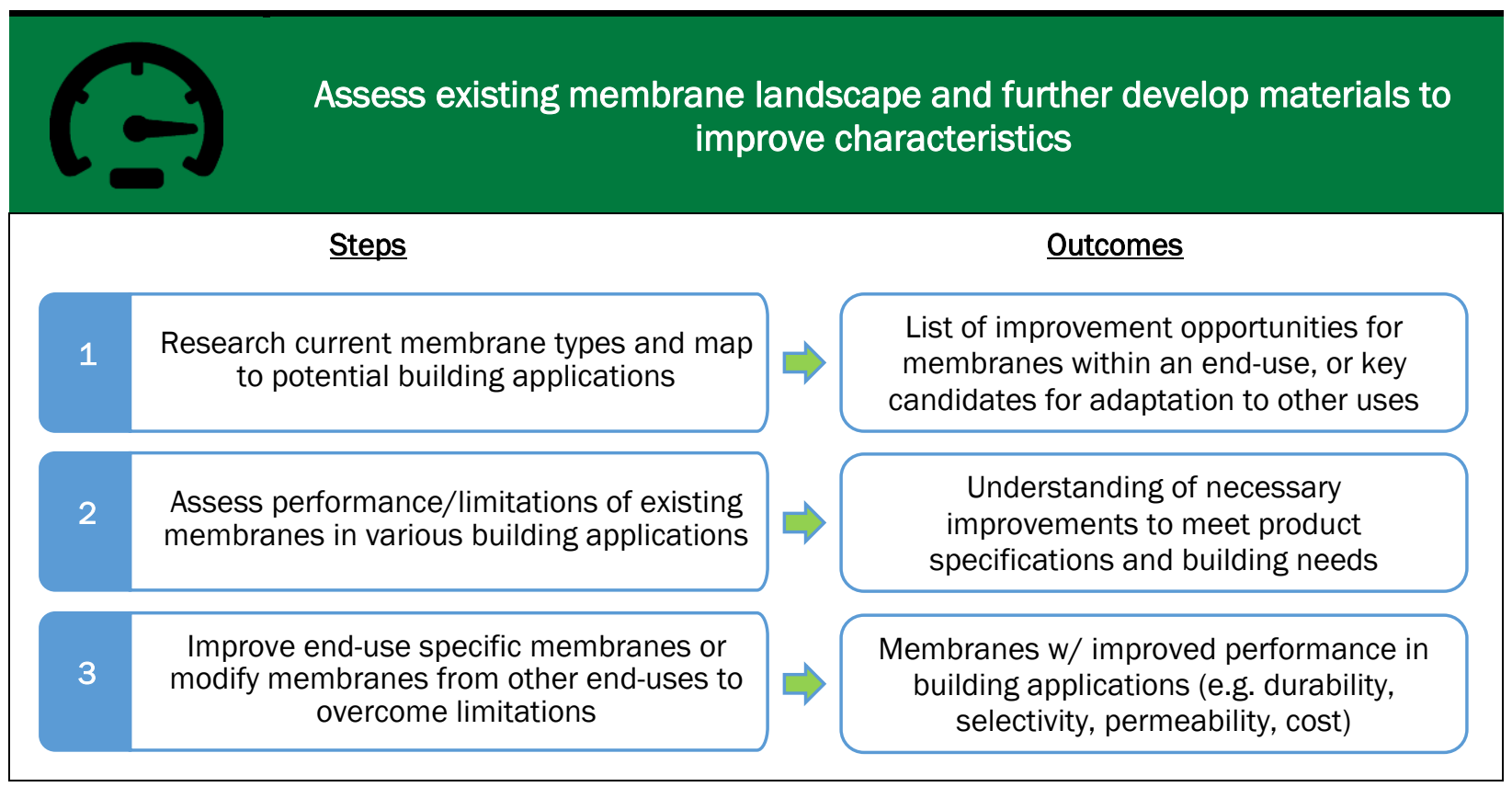

Countless membranes exist each for a different application or end use, with different performance characteristics that are specifically suited to that application. Stakeholders have suggested that the breadth of membranes available is not well documented and thus is difficult to leverage during membrane development without duplication of research. As such, there is a need to aggregate all available data on existing membranes and evaluate further those that are likely fits for building applications. For those membranes, it is possible to then identify specific improvement opportunities to optimize performance of a tailored system for buildings applications.

Together, industry and researchers can collaborate on improving existing membranes or developing new higher-performing membranes that better meet the needs of building-specific end-use applications. Different factors such as thickness, flux, permeability, and selectivity all impact the overall performance of a membrane and are key considerations for system designers developing new membrane-enabled products. Improving the performance of membranes will not only increase the efficiency of end-use applications, but could also facilitate the membrane design process such that membrane-enabled solutions become less time-intensive and costly to develop.

\subsubsection{Sensors}

Table 7 shows the prioritization score, key stakeholders, barriers addressed, steps and outcomes for developing membrane-enabled sensors. 
Table 7: Evaluate performance of, and develop novel applications for membrane-based sensors

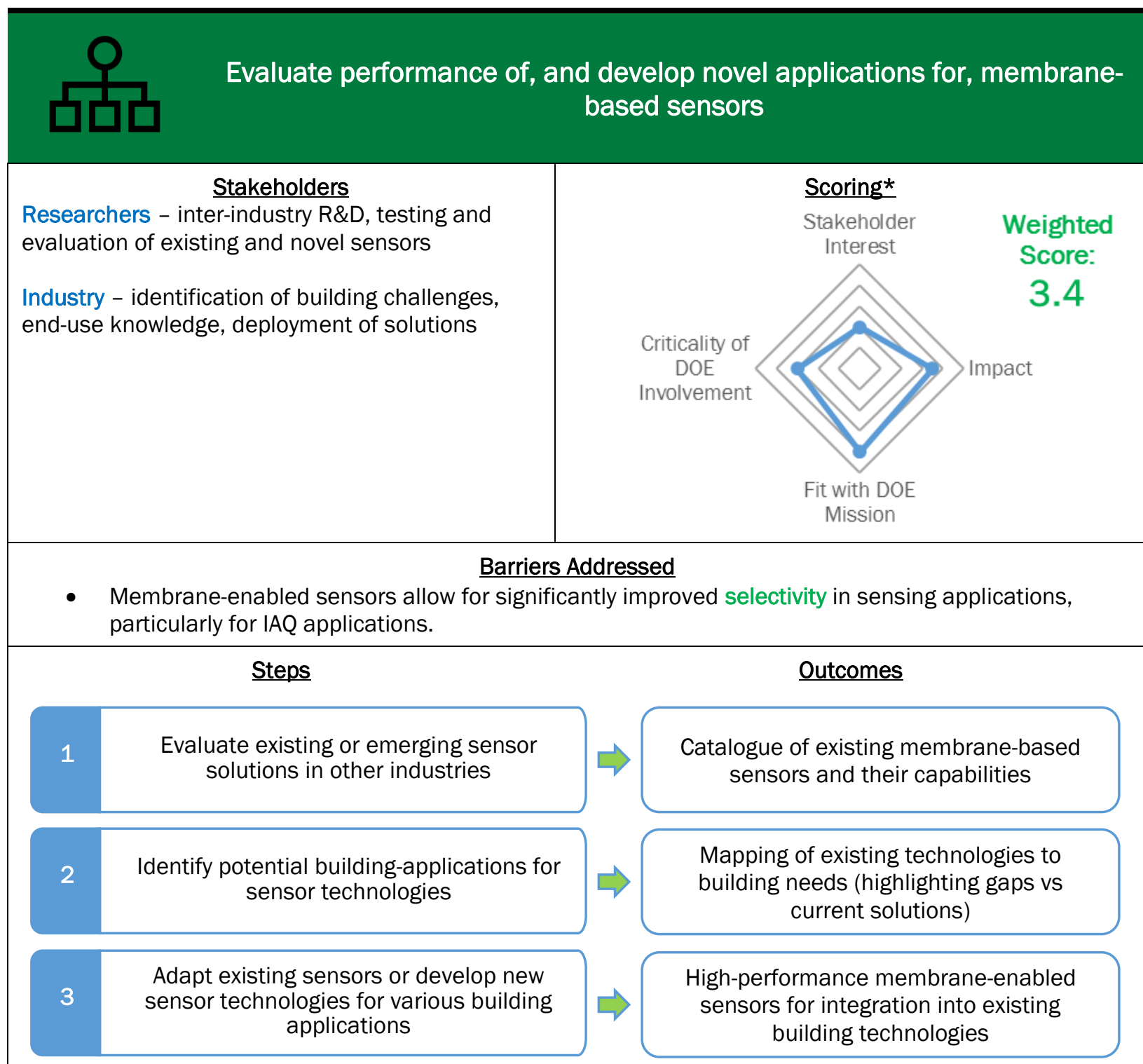

*The stakeholder score reflects the number of votes generated from the stakeholder workshop. This initiative was not fully developed at the time of the meeting and thus, most likely reflects an artificially low stakeholder interest score.

Membrane-enabled sensors are a good fit for integration with existing and novel applications in buildings. As smart buildings and the internet of things (IoT) mature and evolve, low-cost sensors, which are envisioned to be enabled by membranes will be a key foundational, enabling technology.

Stakeholders suggest that membrane-enabled sensors have not yet reached a high level of commercial viability, despite the high levels of interest from the sensors community. Existing sensing technologies cannot act in real time due to delays in the measuring process and typically have low selectivity (except for gas chromatography). Membrane-enabled sensors have the potential to offer a simpler way to achieve real-time gas sensing to detect specific gasses or vapors present in an environment. These processes are costly and time consuming, making sensing technologies difficult to adopt in building applications that require real-time low- 
cost solutions. These factors, coupled with the limited selectivity for VOCs amongst existing sensor technologies, create a compelling opportunity for membrane-based solutions.

DOE and other industry stakeholders can each play a critical role in the development of these sensors. Stakeholders, however, do suggest that the sensors community is currently distinct from the building technologies community; broader integration and development of cross-industry teams will provide a fundamental foundation for membrane-enabled sensor development. Such teams are in the best position to develop a comprehensive understanding of building-related sensing targets and associated technologies to meet those needs. Novel technologies can apply to a multitude of building applications, including (but not limited to) the following:

- Sensors for indoor air quality (IAQ) evaluation

- Sensors to evaluate when food in refrigerators is perishing

- Humidity sensors in microwaves for improved cooking

- Sensors to evaluate cleanliness of building water (both incoming and greywater)

Additional DOE investment could help remedy the cost discrepancy between the current solutions and membrane-based solutions.

\subsubsection{Scalable Production Methods}

Table 8 shows the prioritization score, key stakeholders, barriers addressed, steps and outcomes for developing more scalable production methods.

Table 8: Develop more scalable membranes and membrane production methods

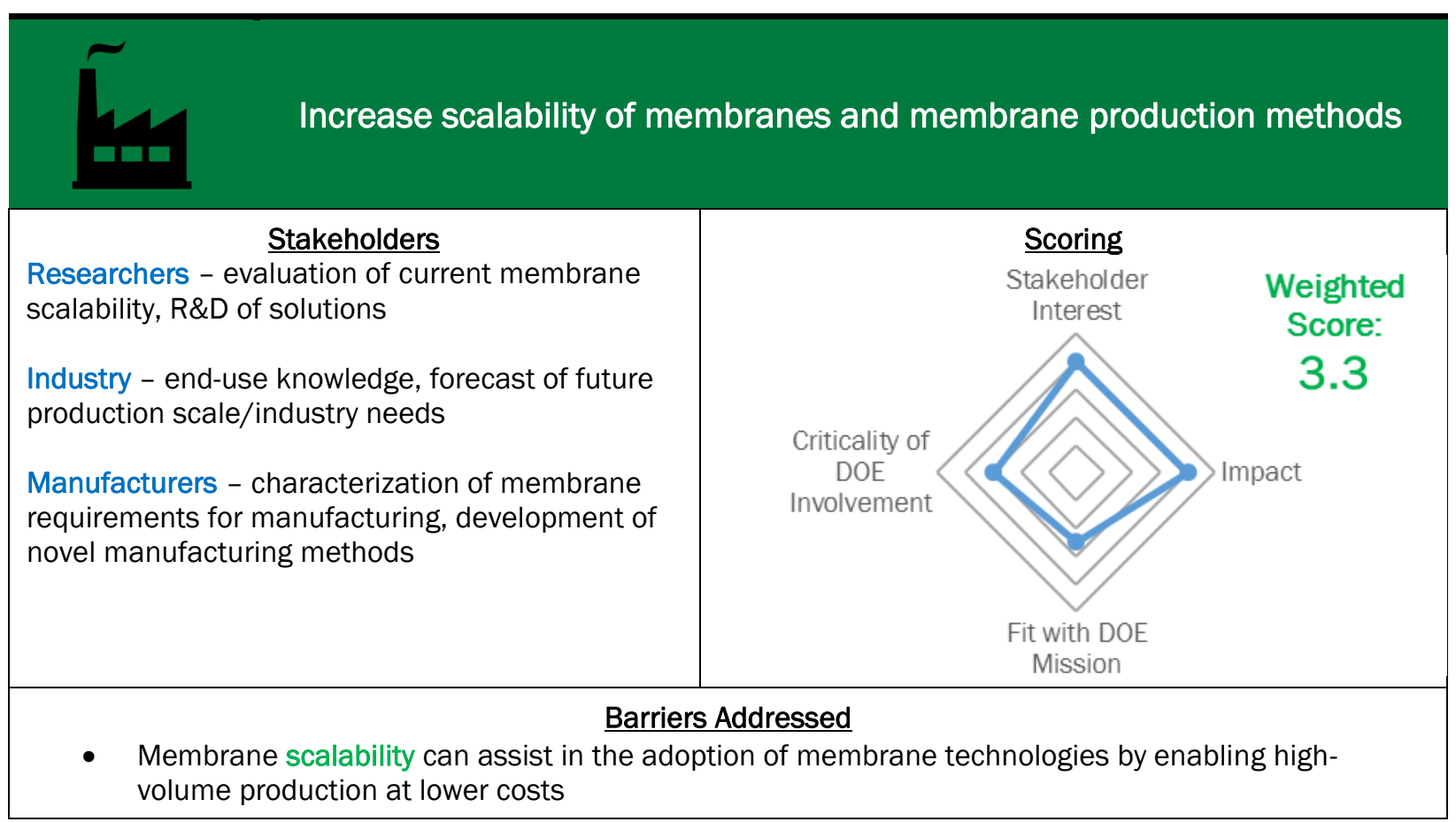




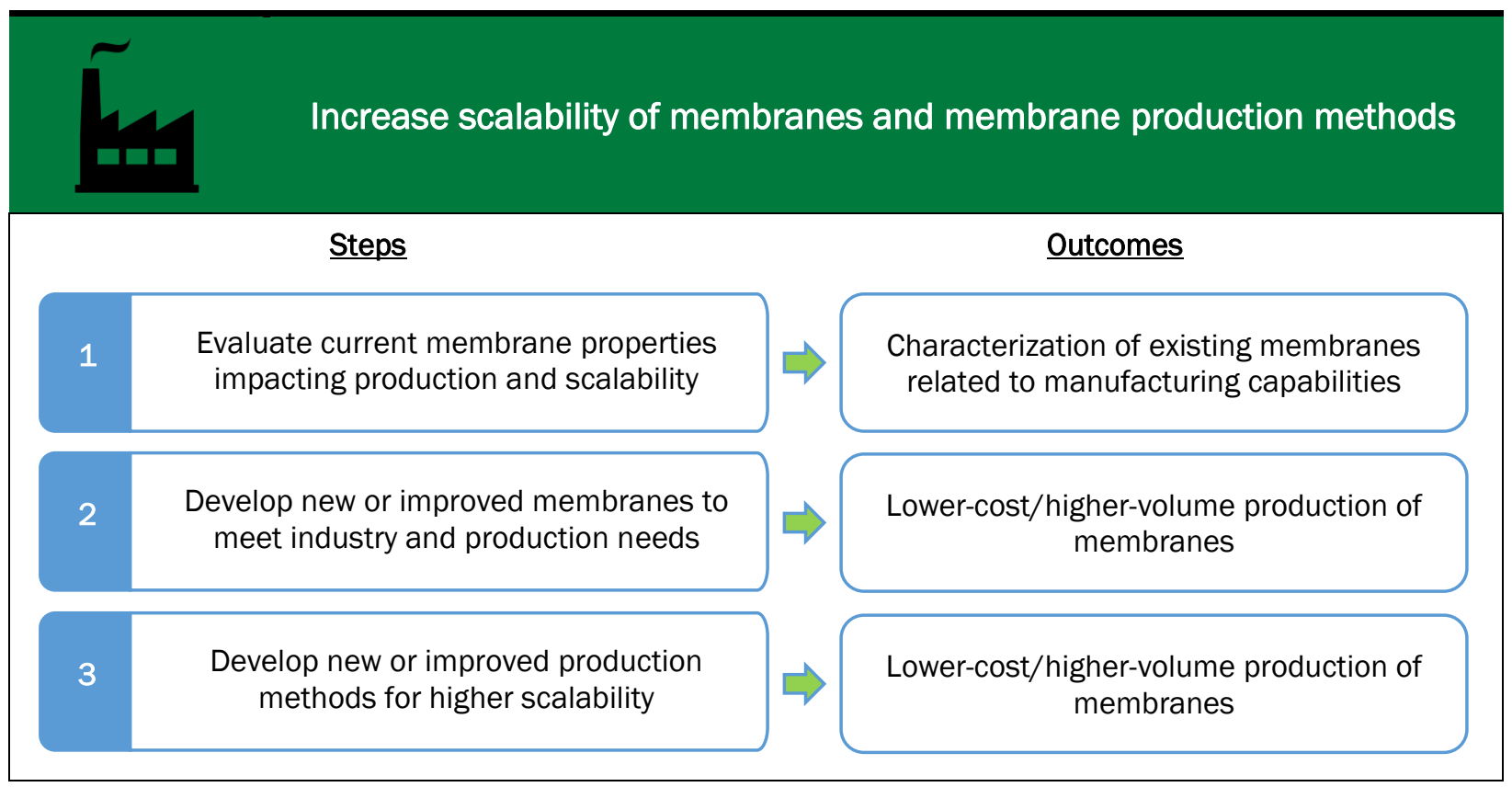

The membranes industry needs improved production scaling techniques to meet the needs of the building enduses. Most applications in buildings require large amounts of the membranes. Current membranes and membrane manufacturing processes are not optimized for large-scale production. Industry can take a twopronged approach at resolving this issue:

1. Develop more scalable membranes - Researchers and industry can evaluate current membranes and identify the properties that influence the scalability of these membranes. With that knowledge, they can work on tailoring membranes such that they are viable for scale up while still meeting the performance demands of their respective applications.

2. Develop new production processes that yield higher membrane square footages - Manufacturers and industry partners can evaluate the state of current production processes used in developing membranes. Developing new production methods or optimizing existing ones can greatly impact the feasibility of producing membranes at the large scale required by several building applications.

Creating a landscape in which manufacturers can consistently provide membranes at high volumes can have a large impact on the adoption rate of membrane-enabled technologies. We expect that larger volume production of membranes will result in reduced membrane cost due to economies of scale. The expected decrease in cost that would result from this measure can also have increase the feasibility of producing more membraneenabled building technologies. 


\subsubsection{Bonding}

Table 9 shows the prioritization score, key stakeholders, barriers addressed, steps and outcomes for developing improved bonding methods.

Table 9: Develop improved bonding methods (including adhesives, fastener-based bonding, and thermal/ultrasonic welding)

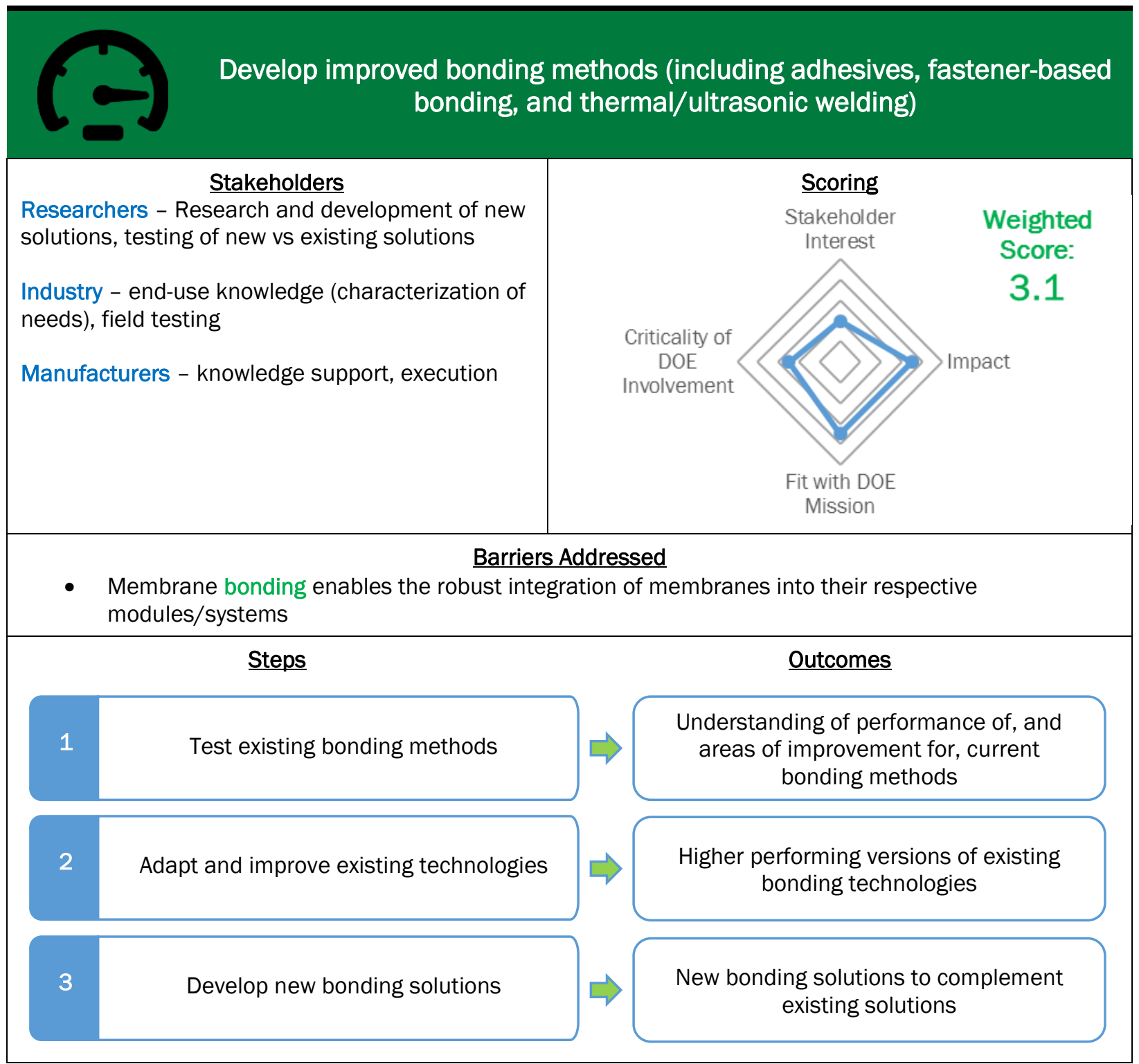

Membrane bonding is a critical part of integration into building systems. Focused efforts by industry stakeholders can result in improved membrane-to-membrane bonding, as well as membrane-to-structuralcomponent bonding.

Membrane-to-membrane bonding enables many membrane customizations that can boost membrane performance (e.g. multiple layers of membranes, each with a distinct function). Multi-layered membranes are more durable and can offer higher levels of selectivity. Membrane researchers are also researching the 
possibility of leveraging multilayer membranes in error proofing by offering a redundant layer if the primary membrane fails. These operations all require one membrane to be bonded to another.

Membrane-to-structural-component bonding, perhaps the more challenging of the two bonding types, is difficult to achieve without damaging or degrading the membrane. In all practical applications, a membrane must be integrated into an existing building system, via a package or module. The success of the integration is dependent on the bonding methods.

DOE and other industry stakeholders can have a large impact on the ease of membrane integration through the development of new or improved:

- Adhesives

- Fastener-based bonding

- Thermal or ultrasonic welding

These improved (or novel) methods can ultimately lead to simpler integrations of membranes into building technologies.

\subsubsection{Boundary Layer Impacts}

Table 10 shows the prioritization score, key stakeholders, barriers addressed, steps and outcomes for reducing boundary layer impacts.

Table 10: Develop improved methods for accounting for and reducing boundary layer impacts in membrane module designs

\begin{tabular}{|l|l|}
\multicolumn{2}{|c|}{$\begin{array}{c}\text { Develop improved methods for accounting for and reducing boundary } \\
\text { layer impacts in membrane module designs }\end{array}$} \\
$\begin{array}{l}\text { Researchers - research and development, } \\
\text { modeling of boundary layer impacts, design and } \\
\text { execution of system-impact tests }\end{array}$ \\
$\begin{array}{l}\text { Industry - development and } \\
\text { utilization/deployment of tools, development of } \\
\text { system performance targets }\end{array}$
\end{tabular}




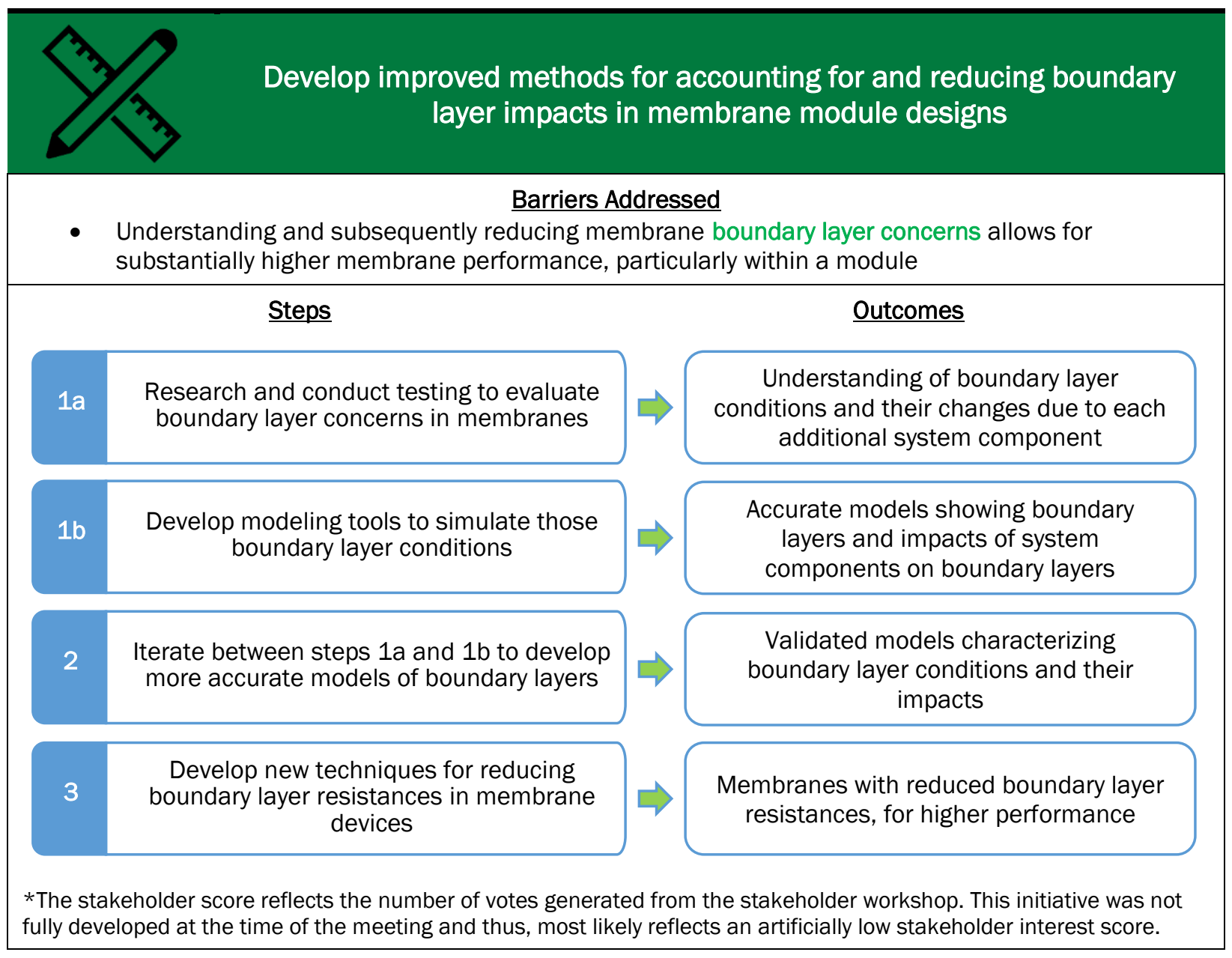

Evaluating boundary layer conditions and developing modeling tools to accurately predict those conditions is important to system designers when characterizing membrane system efficiency. This is particularly relevant to membranes with low permeance, as they tend to be characterized by higher boundary layer resistances.

Decreasing boundary layer resistances has a disproportionately higher impact on system performance as compared to improvements in membrane permeance. As such, a reduction in boundary layer resistance of $10 \%$, for example, will result in better performance than a $10 \%$ increase in membrane permeance. Investments in understanding and improving boundary layer conditions, therefore, could ultimately yield significant improvements to membrane systems.

Industry and researchers can collaborate to evaluate membrane boundary layer conditions and develop modeling tools capable of simulating those conditions in various module configurations. The knowledge and tools resulting from such an initiative would help industry in designing better modules that limit the impact of boundary layer conditions.

\subsubsection{Novel Production Methods}

Table 11 shows the prioritization score, key stakeholders, barriers addressed, steps and outcomes for developing novel production methods. 
Table 11: Develop novel production methods for membranes and membrane systems

\begin{tabular}{|c|c|c|c|}
\hline \multicolumn{4}{|c|}{$\begin{array}{c}\text { Develop novel production methods for membranes and membrane } \\
\text { systems }\end{array}$} \\
\hline \multicolumn{2}{|c|}{$\begin{array}{l}\text { Stakeholders } \\
\text { Researchers - Research and development of } \\
\text { novel methods, evaluation of potential to adapt } \\
\text { novel methods from other industries } \\
\text { Industry - end-use knowledge, identification of } \\
\text { needs } \\
\text { Manufacturers - knowledge support, feasibility } \\
\text { assessment of adopting novel technologies }\end{array}$} & $\begin{array}{l}\text { Scoring } \\
\text { Stakeholder } \\
\text { Interest } \\
\text { ticality of } \\
\text { DOE } \\
\text { olvement }\end{array}$ & $\begin{array}{l}\text { Weighted } \\
\text { Score: } \\
3.1\end{array}$ \\
\hline \multicolumn{4}{|c|}{$\begin{array}{l}\text { Barriers Addressed } \\
\text { nproved customization of membranes and ultimately, improved }\end{array}$} \\
\hline & Steps & Outcomes & \\
\hline 1 & $\begin{array}{l}\text { Identify novel production methods in other } \\
\text { industries }\end{array}$ & $\begin{array}{l}\text { List of production meth } \\
\text { adapted to membrane }\end{array}$ & $\begin{array}{l}\text { at can be } \\
\text { opment }\end{array}$ \\
\hline 2 & $\begin{array}{l}\text { Characterize and develop both mechanical } \\
\text { and chemical production methods }\end{array}$ & $\begin{array}{l}\text { Mechanical methods (e } \\
\text { embossing, nanoprint } \\
\text { methods (e.g. in-situ }\end{array}$ & $\begin{array}{l}\text { printing, } \\
\text { hemical } \\
\text { ation) }\end{array}$ \\
\hline 3 & $\begin{array}{l}\text { Evaluate performance of novel } \\
\text { methodologies }\end{array}$ & $\begin{array}{r}\text { Cost-benefit understa } \\
\text { production methods rela } \\
\text { ones }\end{array}$ & $\begin{array}{l}\text { of novel } \\
\text { traditional }\end{array}$ \\
\hline 4 & Deploy solutions & $\begin{array}{l}\text { Specialized manufactur } \\
\text { more tailored me }\end{array}$ & $\begin{array}{l}\text { ilities for } \\
\text { hes }\end{array}$ \\
\hline
\end{tabular}

Many industries are seeing significant advances in manufacturing technologies. With the decreasing cost of such technologies as 3D printing, there is an opportunity for more creative production methods in the membranes space. Novel production methods can be either mechanical or chemical in nature. Examples of such technologies include but are not limited to the following:

- 3D printing - 3D printing of membranes can result in more intricate membrane designs and, therefore, better integration into membrane modules with complex geometries.

- Nanoprinting - Advances in nanoprinting technologies could yield membrane manufacturing processes that can manipulate membrane nanostructure for more tailored performance. 
- Embossing - Embossing technologies could impart more intricate geometries on membranes. The HVAC industry is particularly interested in embossing for the potential to create membranes with built in airflow channels.

- In-situ formation of membranes - yields asymmetric membranes, wherein a dense small-pore layer is formed simultaneously to a porous support. This type of production can enable industry to tackle more specific challenges such as the formation of supported-membranes directly within a membrane module.

Manufacturers can offer many insights on the emerging production trends in other industries. Researchers can focus on adapting these technologies to membrane and membrane module development. These improved methods will offer industry more flexibility both in the types of membranes they can produce and in the types of applications and challenges to which they can deploy membrane-based solutions.

\subsubsection{Non-Potable-Water Processing}

Table 12 shows the prioritization score, key stakeholders, barriers addressed, steps and outcomes for improving non-potable-water processing.

Table 12: Improve efficiency of building-scale and larger non-potable-water processing

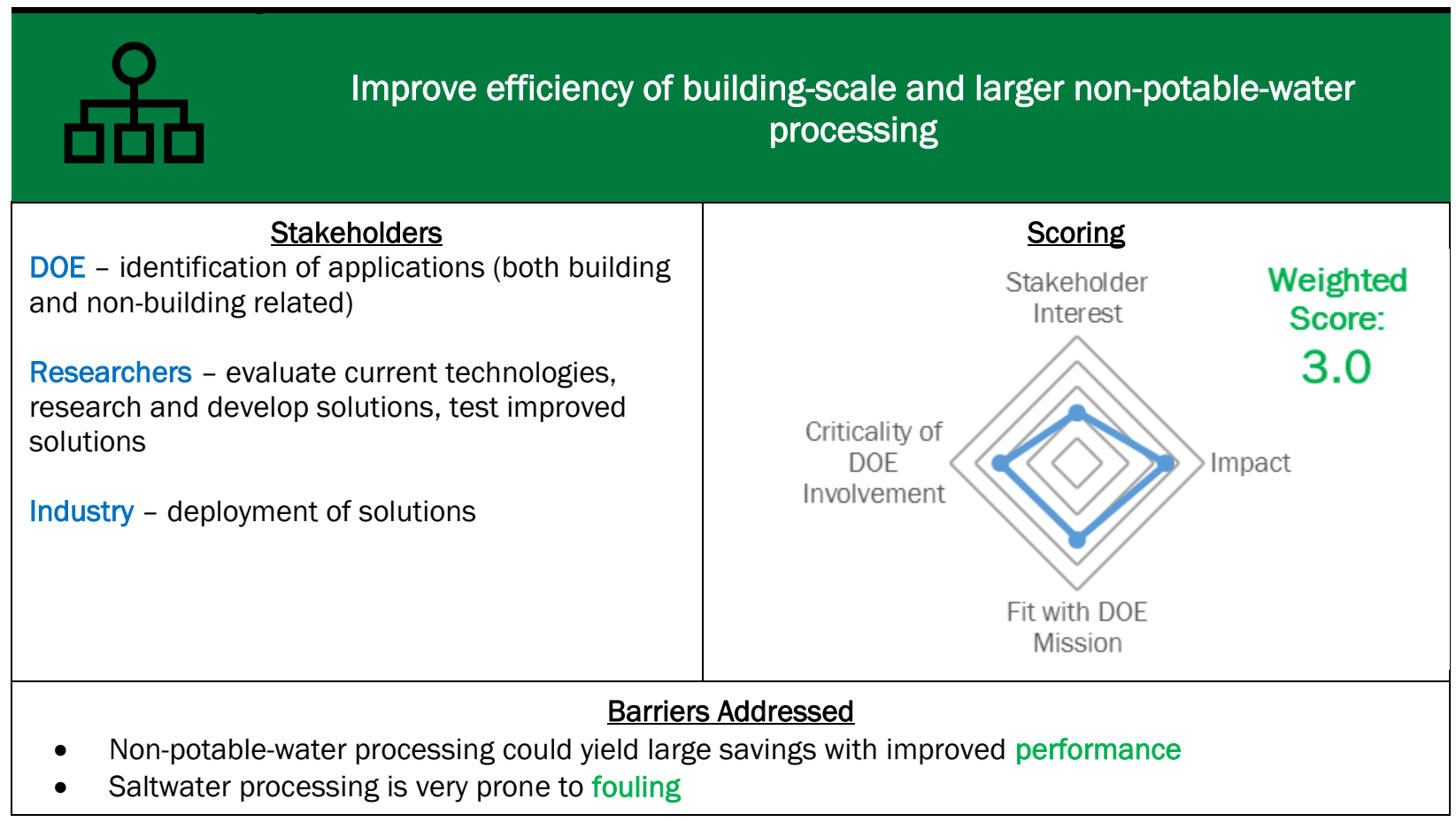




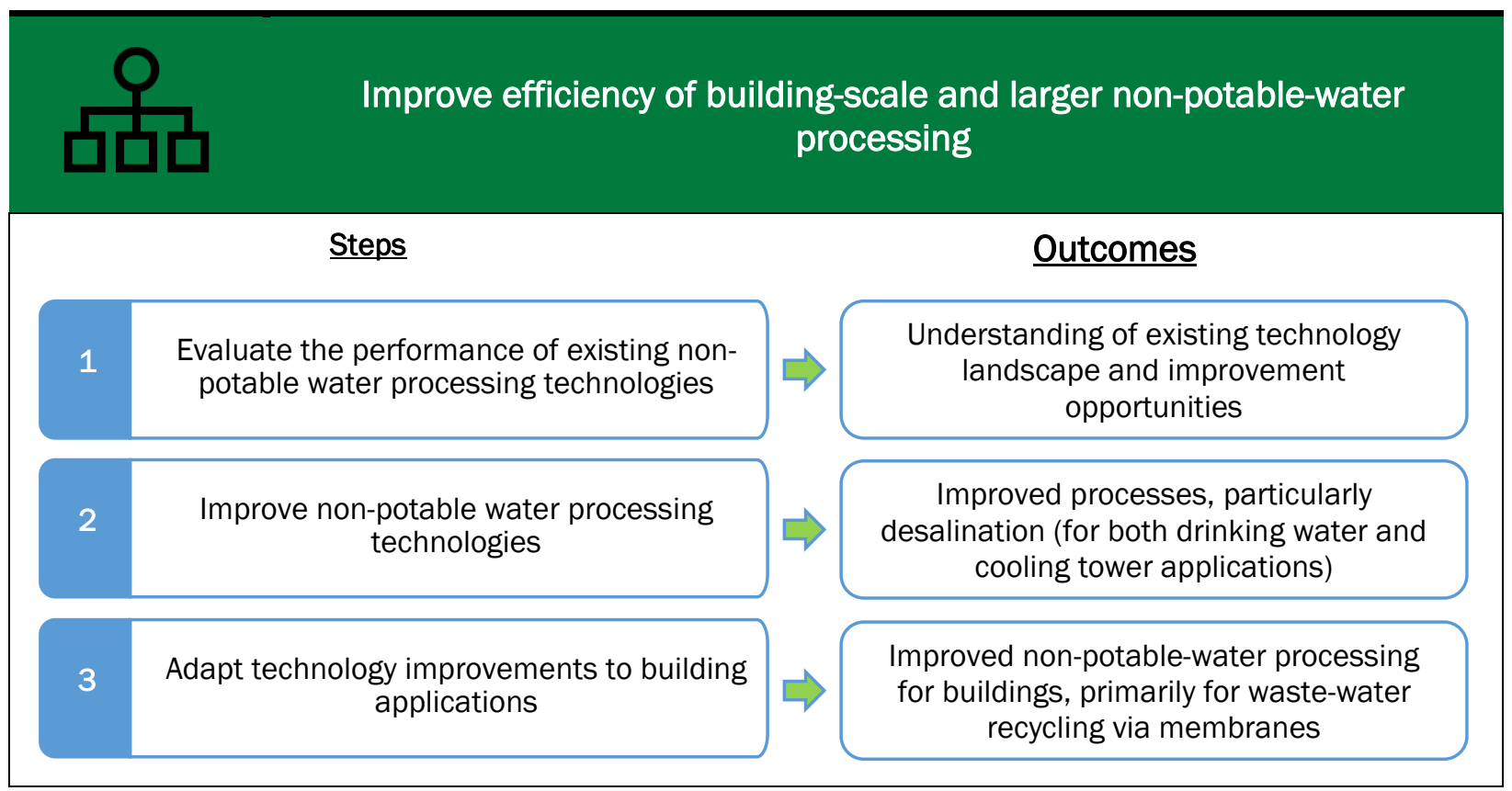

Membranes can enable water and energy efficiency improvements for non-potable-water processing for or from buildings. There are numerous applications for DOE to explore, both in building and in larger (e.g., industrial) applications. Key applications include but are not limited to:

- Greywater recycling - building greywater can be processed and reused in different non-potable applications depending on the purity level.

- Seawater cooling towers - to minimize the consumption of freshwater, industry can and has used seawater for cooling towers, but the salt content causes scaling. Membranes can be utilized to control the fouling inside the towers or to pretreat and desalinate water prior to its use in the tower.

- Desalination for drinking water - desalination plants are on the rise both globally and domestically. Historically large consumers of energy, these systems can benefit from any level of membraneenabled system-efficiency improvements to provide a significant efficiency impact.

Further developing membrane-enabled non-potable water processing technologies will require a closer look at the existing technologies and at the ways in which improved separations can add value. DOE and industry can then converge on the most impactful applications and adapt or develop the technologies to increase efficiency. 


\subsection{Tier II Initiatives}

Table 13 lists all the Tier II initiatives with a brief description and a list of barriers addressed by the initiative.

\section{Table 13: Tier II Initiatives}

\begin{tabular}{|c|c|c|}
\hline ID & $\begin{array}{l}\text { Initiative } \\
\text { Barrier Addressed }\end{array}$ & Objective/Description \\
\hline \multirow{2}{*}{11} & $\begin{array}{l}\text { Initiative: Develop improved Metal Organic } \\
\text { Frameworks (MOFs) }\end{array}$ & \multirow{2}{*}{$\begin{array}{l}\text { Metal Organic Frameworks (MOFs) should be further explored to develop new transport } \\
\text { pathways and separations mechanisms. MOFs allow for improved control of chemical } \\
\text { properties (as compared to standard membranes), making them an interesting solution } \\
\text { to specific use-cases such as adsorption for solar-based dehumidification, for example. }\end{array}$} \\
\hline & $\begin{array}{l}\text { Barrier Addressed: offer more customization of } \\
\text { membranes }\end{array}$ & \\
\hline \multirow[t]{2}{*}{12} & $\begin{array}{l}\text { Initiative: Develop new ceramic membranes and } \\
\text { adapt existing ceramic membranes to building } \\
\text { applications }\end{array}$ & \multirow{2}{*}{$\begin{array}{l}\text { Ceramic membranes offer a more robust alternative to standard membranes. These } \\
\text { membranes, commonly used in oil and gas and other industries, can be adapted to offer } \\
\text { more durable solutions for building systems, including wastewater applications. }\end{array}$} \\
\hline & $\begin{array}{l}\text { Barrier Addressed: provide more durability than } \\
\text { standard membranes }\end{array}$ & \\
\hline \multirow[b]{2}{*}{13} & Initiative: Develop composite membranes & \multirow{2}{*}{$\begin{array}{l}\text { Composite membrane materials are ones that enable both support and transport } \\
\text { functions within a membrane. As compared to hybrid materials (see Initiative 18), which } \\
\text { achieve a similar effect by combining multiple materials, composite membranes leverage } \\
\text { a singular material (e.g. one with multiple layers at a molecular level, each performing a } \\
\text { separate function) to serve multiple functions for improved overall membrane } \\
\text { performance and durability. }\end{array}$} \\
\hline & $\begin{array}{l}\text { Barrier Addressed: impacts both durability and } \\
\text { scalability of membranes }\end{array}$ & \\
\hline \multirow[b]{2}{*}{14} & $\begin{array}{l}\text { Initiative: Evaluate and improve upon performance of } \\
\text { non-membrane based separation technologies }\end{array}$ & \multirow{2}{*}{$\begin{array}{l}\text { Given the bias of the stakeholder workshop group towards membrane technologies, } \\
\text { other separation technologies did not receive much attention. It is important to note, } \\
\text { however, that there are several separation technologies (e.g. adsorption, distillation, } \\
\text { sieving, etc.) that could benefit from evaluation-driven improved performance. In relevant } \\
\text { environments, additional R\&D can help guide the industry on which are the key areas for } \\
\text { improved selectivity and performance of separation technologies. }\end{array}$} \\
\hline & $\begin{array}{l}\text { Barrier Addressed: needed for higher performance of } \\
\text { separation technologies }\end{array}$ & \\
\hline \multirow[b]{2}{*}{15} & $\begin{array}{l}\text { Initiative: Evaluate performance of various membrane } \\
\text { form-factors and develop new or improved solutions }\end{array}$ & \multirow{2}{*}{$\begin{array}{l}\text { Current membrane form-factors and configurations need further performance } \\
\text { evaluations to guide the development of novel configurations (e.g. "hairy" membranes } \\
\text { that extend into the feed stream) to meet any performance gaps. Different form factors } \\
\text { (e.g. frame, hollow fiber, etc.) operate differently in different end uses, thus new and } \\
\text { existing form factors must be tailored to and mapped to (respectively) specific building } \\
\text { applications. }\end{array}$} \\
\hline & Barrier Addressed: provides more customization & \\
\hline
\end{tabular}


Initiative: Develop prescribed methodology for evaluating membrane-scale-up-feasibility

\section{Barrier Addressed: critical to scalability}

Initiative: Develop new hybrid materials and adapt existing hybrid materials to building applications

17

Barrier Addressed: Hybrids add to the customization of membranes

Initiative: Develop methods for conducting accelerated-lifecycle membrane studies

Barrier Addressed: increases the technology Level of Confidence

Initiative: Develop improved modeling tools specifically for membranes and membrane systems

Barrier Addressed: Makes for easier design of membranes
Objective/Description

DOE should develop test methods to quantitatively evaluate the scalability of potential new solutions. Conducting these scalability assessments early in the development process provides an avenue through which researchers can consider scalability concerns early in the development of new membranes.

Research is needed to improve the processes by which available membrane materials can be combined to achieve lower cost, higher performance, or both. This initiative applies to organic and inorganic integration, as well as integration of polymers of commerce/materials from different suppliers. Research to overcome geometric constraints (e.g. tube vs flat sheet), as well as the chemical instabilities resulting from combining materials can greatly impact the development of hybrid materials.

Industry requires the ability to test for product longevity and durability via accelerated long-duration testing. Such test results could demonstrate a quantitative level of confidence in these emerging technologies.

Industry requires improved modeling tools (e.g. computational fluid dynamics) for many membrane-related tasks, including: design of heat and mass exchangers, membrane module design, as well as simulation of boundary layers in membrane systems. The outputs of such tools could ultimately result in a membrane-enabled design guide that highlights best practices for membrane-system design. 


\section{Appendix A: Building-System Membrane and Separation Technology Descriptions}

The following subsections add context to the science enabling the use of membranes and separation technologies in building systems. Each subsection highlights the status or target applications for each technology, as well as the any recent R\&D measures. Stakeholder interviews further guided some of the content in these sections; given the expertise of our interviewees, HVAC-related technologies are described in more detail relative to others in the list. The technologies below are intended to highlight sample membrane use-cases in a few specific building applications, rather than provide an exhaustive list of measures and their associated scientific minutiae.

\subsection{HVAC}

\subsubsection{Humidity Control}

\subsubsection{Dehumidification}

Membrane technologies can be applied to the dehumidification of airstreams in HVAC systems as an integrated component or as standalone systems. One such embodiment involves a water-vapor selective membrane, which can discriminate between water and the individual constituents of air such as oxygen, nitrogen, and argon. The membrane selectivity is driven by two factors: pore size and electrical characteristics. Particles larger than a few nanometers are unable to pass through the pores of the membrane. The membrane, which contains numerous paired charges, further restricts molecules from passing if they are of an even charge distribution. Given these selectivity parameters, a concentration difference between the two faces of the membrane results in water vapor exclusively permeating the membrane. A vacuum or other pressure gradient creates the concentration difference to drive permeation and extract water vapor from humid inlet air.

The resulting air is dry, which reduces the required cooling capacity for the building (reducing capital costs) and increases efficiency by eliminating the need for overcooling air to the dew point to extract moisture and then reheating to the setpoint. Membrane dehumidification systems can also be employed as independent products, either ducted with the rest of the HVAC, or standalone for room applications.

\section{Table 1: [Appendix] Membrane Dehumidification Summary}

Applications and Status

Recent R\&D
Central AC independent humidity controls; being developed by Dais (NanoAir product $^{8}$ Small-scale dehumidification - Dehumidification of refrigerator crisper drawers, electronics, or museum displays; being commercialized (e.g., Xergy) ${ }^{9}$

ARPA-e - \$3.38MM - ADMA Products, Inc. - Membrane Dehumidifier - 2010$2014^{10}$

\subsubsection{Humidification}

Humidification can also be achieved via a membrane; wherein a water reservoir, in conjunction with a vaporselective membrane, can be used to humidify an airstream. The pressure differential between the dry airstream and the water drives water vapor to permeate through the membrane from the reservoir into the airstream. This

\footnotetext{
${ }^{8}$ More info at: http://www.daisanalytic.com/applications/nanoair/

${ }^{9}$ Xergy Inc., Humidity Controls, available: http://www.xergyinc.com/micro-climate-humidity-control.php

${ }^{10}$ ARPA-e Research via BEETIT program funding for ADMA Products, available: https://arpa-e.energy.gov/?q=slick-sheet-project/membranedehumidifier
} 
transfer of moisture can also be vacuum driven for larger scale humidification applications. Table 2 describes key characteristics of the application.

Table 2: [Appendix] Membrane Humidification Summary

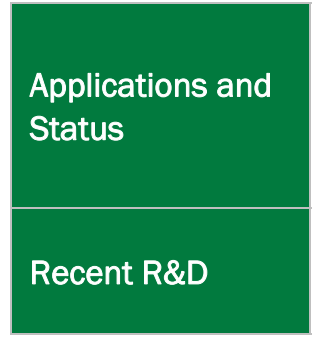

- $\quad$ HVAC, relative humidity control - no known HVAC products available (excluding ERV)

- Humidification of oxygen airstreams for healthcare patients and of dry gas streams for fuel cells; products available from Pentair, fumatech, perma pure, among others.

- $\quad$ Research to determine the feasibility of applying membrane based humidifiers for fuel cell applications. ${ }^{11}$

\subsubsection{Evaporative Cooling}

A water selective membrane, as described in section A.1, can also be used to cool air via evaporation when water is placed against the membrane. A pressure gradient across the membrane, again, causes water to permeate through the membrane. Given the properties of the membrane, water can only permeate as a gas, in the form of water vapor. The phase change that the water undergoes when transiting through the membrane cools the remaining liquid water.

In practice, membrane-based cooling can be applied in the form of a water channel lined with a membrane. As the water in the channel permeates across the membrane, the water in the channel cools down and the chilled water can be circulated in a cooling loop to cool air in one or more air handling units. Table 3 describes key characteristics of the application.

Table 3: [Appendix] Membrane Cooling and Dehumidification Summary

Applications and Status

Recent R\&D
- $\quad$ 7AC Technologies ${ }^{12}$ products underdevelopment

- Technology depicted in Figure 1

- ARPA-e - $\$ 681,000$ - Dais Analytic Corp. Nanotechnology membrane-based dehumidifying for space cooling and refrigeration - 2010-2012

\footnotetext{
${ }^{11}$ Nielsen et al. "Modeling of a Membrane Based Humidifier for Fuel Cell Applications Subject to End-of-Life Conditions" http://www.ep.liu.se/ecp/108/008/ecp14108008.pdf

12 7AC Tech, details available at: http://7actech.com/our-solution/

${ }^{13}$ ARPA-e Research via BEETIT program funding for Dais Analytic Corp., available: https://arpa-e.energy.gov/?q=slick-sheetproject/dehumidifying-air-cooling-refrigeration
} 


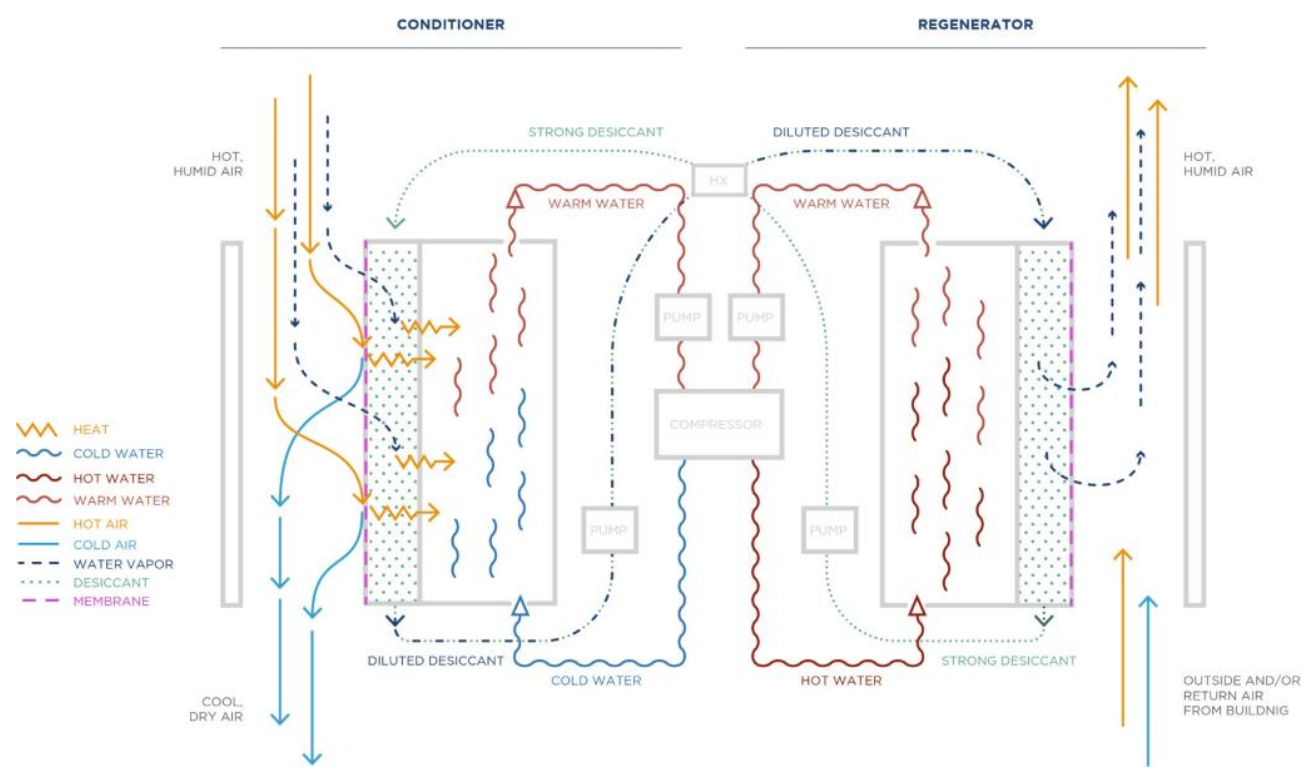

Figure 1: [Appendix] 7AC Tech Membrane Cooling and Dehumidification ${ }^{14}$

\subsubsection{Energy Recovery Ventilation}

Energy recovery ventilators employ membrane technologies in adsorption cycles to improve operating efficiencies. In a cooling application, hot, humid air enters the system on the inlet side to be cooled and dehumidified. The inlet air is brought into contact with a desiccant wheel, commonly referred to as an enthalpy wheel, to achieve a dehumidification of the air. Typically, the desiccant wheel, which rotates slowly for increased contact with the air, is characterized by a desiccant applied to a molecular sieve. These wheels, however, can be made of a membrane to overcome the desiccant's potential for detaching from the sieve, lowadsorption rates, and necessity to rotate. In such an application, the membrane is a water-vapor passive barrier that works to extract water vapor from the inlet air. Thus, air that has passed through the membrane-lined desiccant wheel is dry and warm. Furthermore, through the adsorption of the moisture vapor, the latent heat of condensation is released, thereby cooling the airstream. The air is then counter flowed against waste air from the building. The barrier separating these two airstreams can include a membrane to allow for the transfer of heat from the inlet stream to the outlet stream. The cycle can also be reversed to heat air.

Membrane-based ERVs enable exchange of both sensible and latent heat loads without the need for moving parts as are commonly used in today's enthalpy wheels. The membrane modules are loaded such that exhaust air and outdoor air streams are on alternating sides of the membranes to exchange sensible heat and to enable the transfer of water vapor across the membrane. Other solid-state alternatives generally only exchange sensible heat between the air streams. ${ }^{15}$ Energy transfer effectiveness can reach $70 \%$ for sensible and $60 \%$ for latent. ${ }^{16}$ Table 4 describes key characteristics of the application.

\footnotetext{
${ }^{14} 7 \mathrm{AC}$ Tech

${ }^{15}$ Energy Efficiency Emerging Technologies database, accessible at: http://e3tnw.org/ItemDetail.aspx?id=461\#citation_1335

${ }^{16}$ Trane Engineers Newsletter Live: Air-to-Air Energy Recovery, available:

https://www.trane.com/content/dam/Trane/Commercial/global/products-systems/education-training/continuing-education-gbci-aia-pdh/Air-toAir-Energy-Recovery/app-cmc046-en material vod.pdf
} 
Table 4: [Appendix] Membrane ERV Summary

Applications and

\section{Status}

Recent R\&D and Examples
- $\quad$ ERV modules for retrofit or new installations; available from multiple small manufacturers: Dais Analytic (process depicted in Figure 2), ${ }^{17}$ dPoint, ${ }^{18}$ Mitsubishi, ${ }^{19}$ Panasonic, ${ }^{20}$ and Building Performing Equipment, Inc. ${ }^{21}$

- Public R\&D appears to be limited

- Membrane-based commercial AC - \$1.2MM DOE Funding to Dais Analytic, with partners ORNL and Xergy; Target 7.5Ton TRL-6 prototype with a primary energy COP of 2.0 (54-89\% better than current technology) by Sept. 2017.22

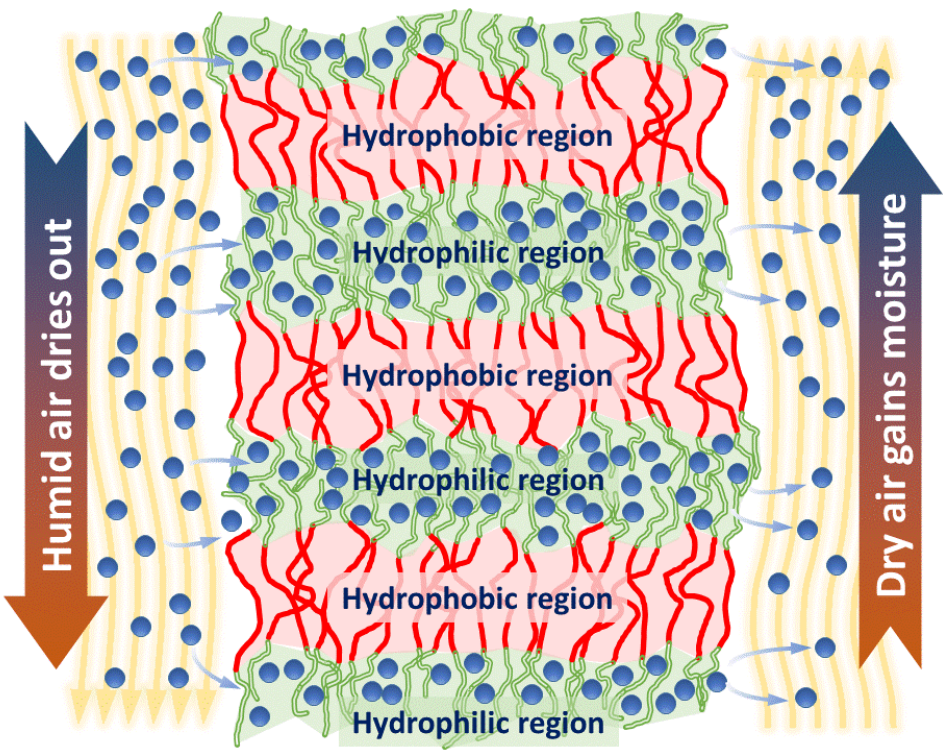

Figure 2: [Appendix] Dais ConsERV Membrane ERV23

\subsubsection{ERV and Power Generation}

Membrane based ERV systems can be paired with fuel cells to simultaneously provide cooling and generate electricity. Table 5 describes key characteristics of the application.

Table 5: [Appendix] Membrane ERV and Power Generation Summary

\section{Applications and Status}

Recent R\&D
- BeCool Roof Top Packaged A/C and Heating Unit, under development by BePower Tech $^{24}$

- $\quad$ Schematic of process provided in Figure 3

- $\quad$ Co-developed/based on research from NREL 25

\footnotetext{
${ }^{17}$ Ibid.

${ }^{18} \mathrm{dPoint}$ products details at their website: $\mathrm{https://www.dpoint.ca/}$

${ }^{19}$ Mitsubishi's Lossnay, details available at: http://www.mitsubishicomfort.com/press/press-releases/mitsubishi-electric-hvac-lossnayr-ervsprovide-ventilation-while-recovering-energy

${ }^{20}$ WhisperComfort from Panasonic; available at: http://business.panasonic.com/FV-04VE1.html

${ }^{21}$ Building Performing Equipment, Inc, product details available at their website: http://www.ecoairanywhere.com/

22 "Membrane Based Air Conditioning: 2016 Building Technologies Office Peer Review," Presentation by Brian Johnson, Dais Analytic Corp., April 2016, available: https://energy.gov/sites/prod/files/2016/04/f30/312108_Johnson_040516-1705.pdf

${ }^{23}$ ConsERV product from Dais Analytic, available: www.conserv.com/

${ }^{24}$ Ibid.

25 "Electricity Producing Air Conditioning Systems" NREL, available at: https://www.nrel.gov/workingwithus/assets/pdfs/2015-igf-be-power$\underline{\text { tech.pdf }}$
} 


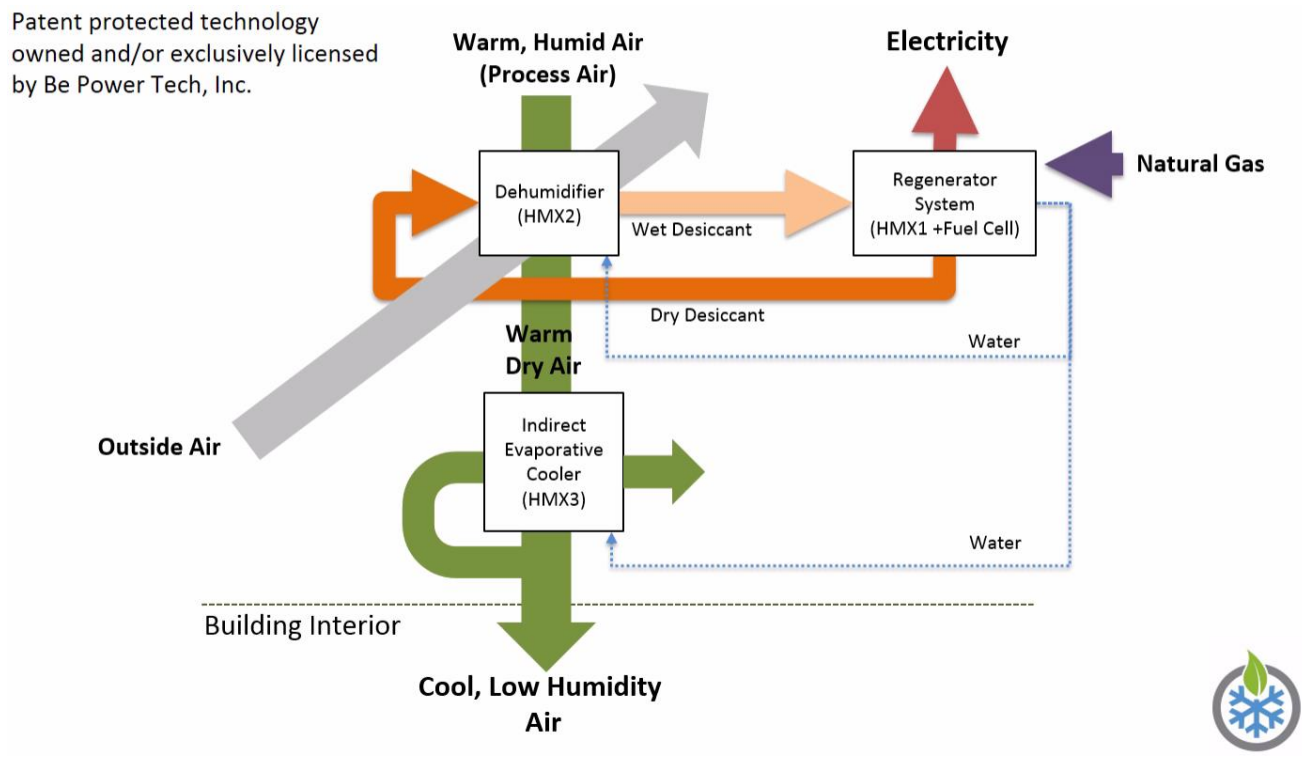

Figure 3: [Appendix] Membrane ERV and Power Generation26

\subsubsection{Electrochemical Compressor}

Electrochemical compressors offer a means for compression that leverages separation processes typical in hydrogen fuel cells. Protons and electrons removed from hydrogen atoms travel across a membrane and recombine to produce pressurized hydrogen. This system thereby enables the use of water as a refrigerant, making electrochemical compressors an environmentally friendly alternative to a standard compressor, which requires the use of refrigerants that may have a potentially high Global Warming Potential (GWP). These membrane-enabled systems are highly efficient and noiseless when compared to their mechanical counterparts. Table 6 describes key characteristics of the application.

Table 6: [Appendix] Membrane-based ECCs Summary

Applications and Status

Recent R\&D
- $\quad$ Xergy Inc. ${ }^{27}$ electrochemical compressor is depicted in Figure 4

- $\quad$ RAC, humidity control for freezers, HPWH,

- "DOE has helped advance state of the art"

- Lab stage formation of composites.

${ }^{26}$ BePower Tech's BeCool RoofTop Packaged A/C and Heating Unit; details available at: https://www.bepowertech.com/technology.html

${ }^{27}$ Ibid. 


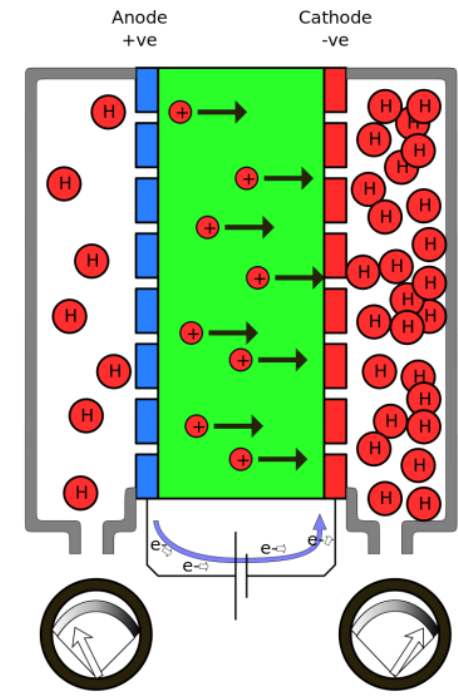

Figure 4: [Appendix] Electrochemical Compressor28

\subsection{Refrigeration}

Table 7 and the following subsections provide detail on separation-enabled refrigeration applications.

Table 7: [Appendix] Membrane Refrigeration Summary

\begin{tabular}{lll|}
\hline Applications & - Absorption Refrigeration Systems \\
& - Non-condensable Gas Removal \\
\hline $\begin{array}{l}\text { Technology } \\
\text { Status }\end{array}$ & $\begin{array}{l}\text { Lab testing for commercialization } \\
\text { - University of Florida } 29\end{array}$ \\
\hline Recent R\&D & DOE/Enerfex 30 \\
& ARPA-e Membrane-based absorption refrigeration systems - University of Florida - \\
& $2.65 M M-2010-2015$
\end{tabular}

\subsubsection{Absorption Refrigeration Systems}

Absorption refrigeration systems (ARS) operate on the principle of extracting heat out of a refrigerated space, rather than pumping cold air into the conditioned space. Typical absorption refrigeration systems are not viable solutions for widespread commercialization due to the cost and size of the heat exchangers involved in the cycle. As such, membrane technologies can have a significant impact in the development of these refrigeration systems.

Ammonia-selective membranes can be used in place of large and costly heat exchangers in ARS systems. An ammonia-water solution is boiled in a generator to separate ammonia gas from the solution. The Ammonia

\footnotetext{
${ }^{28}$ Xergy's Electrochemical Compressor; available at: http://www.xergyinc.com/pcex.php

${ }^{29}$ Saeed Moghaddam "Nanoengineered Membrane-based Absorption Cooling for Buildings using Unconcentrated Solar and Waste Heat" University of Florida.

30 "Membrane Technology to Selectively Remove Entrapped Gases from Process," DOE Office of Industrial Technologies, Available at: https://web.archive.org/save/ embed/http://www.energy.or.kr/up load/iecenter/club00000207 energy/3-10enerfex(Membrane\%20technology).pdf
} 
passes through a membrane and experiences a phase change from either liquid-to-gas on the evaporator or from gas-to-liquid when acting as the condenser. Figure 5 shows a schematic of this process.

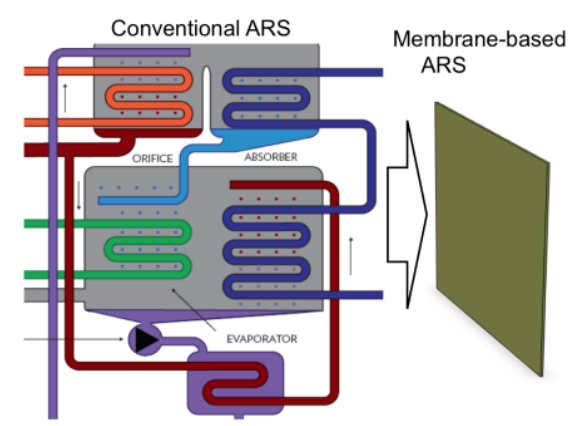

Figure 5: [Appendix] Absorption Refrigeration System ${ }^{31}$

\subsubsection{Non-condensable Gas Removal}

Ammonia based refrigeration systems experience a marked decrease in efficiency when non-condensable gasses are part of the working fluid. The increased pressure required to condense these gasses results in both greater electrical power consumption and reduced refrigeration capacity. Typically, these gasses are removed via the use of an air purger; however, membrane technologies provide an alternative and superior means of purging these gasses. An ammonia selective membrane, applied between the condenser outlet and the compressor inlet, has the capacity to extract these non-condensable gasses. The high-pressure gradient between the compressor and the condenser drives the diffusion of the ammonia vapor through the membrane. The noncondensable gasses separated by the membrane are vented out of the system to the atmosphere. Meanwhile, the pure ammonia retained is pumped back in to the compressor. This resulting pure ammonia entering the compressor greatly minimizes compressor efficiency losses as compared to systems in which non-condensable gasses are fed back in to the compressor. Figure 6 depicts a schematic of the described process.

\footnotetext{
${ }^{31}$ Saeed Moghaddam "Nanoengineered Membrane-based Absorption Cooling for Buildings using Unconcentrated Solar and Waste Heat" University of Florida.
} 


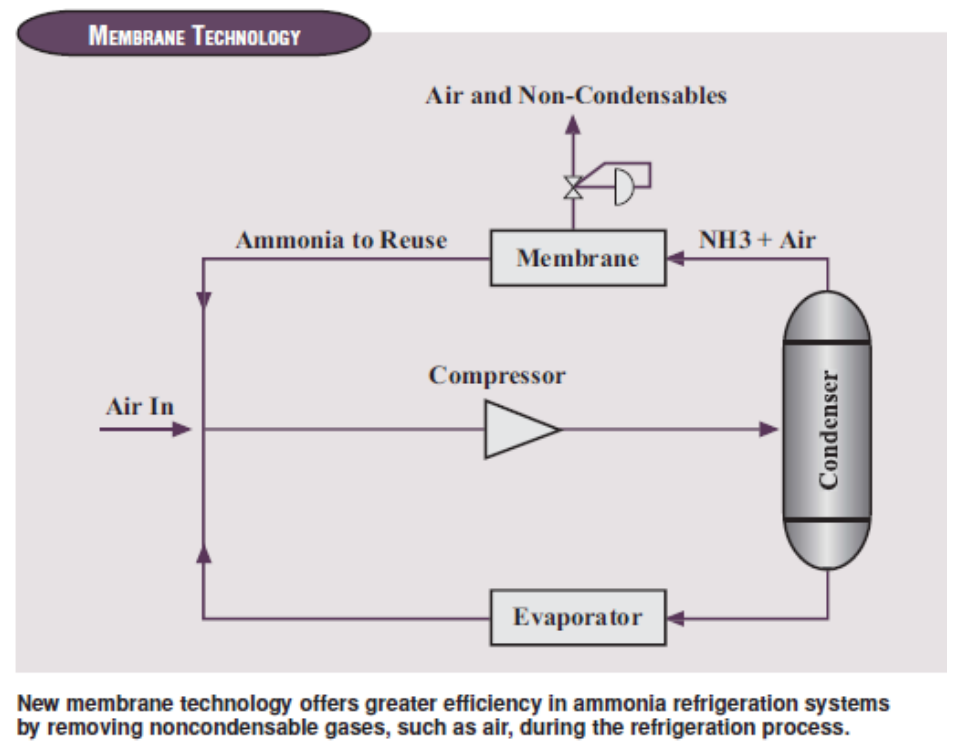

Figure 6: [Appendix] Absorption Refrigeration System ${ }^{32}$

\subsubsection{Improved Preservation of Foods}

Non-energy saving initiatives, such as improved food preservation, can be accomplished with the use of membranes. Vapor selective membranes can be used to prevent dehydration of foods through humidity control. Furthermore, nitrogen selective membranes can prevent oxidation in food through manipulation of oxygen levels in crisper drawers.

Refrigerated food products, particularly produces, undergo deterioration for numerous reasons despite cold temperatures slowing bacterial growth. Dehydration and oxidation contribute a significant amount to the spoilage of foods. Membrane technologies can be applied to address each of these issues in refrigerators. Refrigerator crisper drawers allow for targeted application of membranes for the purposes of dehumidification and oxygen control. As described in the first section, dehumidification can occur by the use of a hydrophilic membrane, which extracts water vapor from the air in the crisper drawer. Oxygen control, however, requires a different type of membrane application. An airstream is passed through a nitrogen selective membrane, resulting in a nitrogen rich stream. This air is then pumped into the crisper drawer. As the nitrogen levels in the drawer increases, the oxygen concentration decreases and, thereby, retards oxidation and the premature browning of refrigerated foods.

\subsection{Power Generation}

\subsubsection{Fuel Cells}

Fuel cells provide a sustainable energy source that makes use of hydrogen fuel and oxygen to produce electricity. Fuel cells are comprised of a Proton Exchange Membrane (PEM), also known as Polymer Electrolyte Membrane, sandwiched between an anode and a cathode. The anode and cathode are made up of platinum particles that are evenly distributed across a supporting layer of carbon particles. The platinum acts as a catalyst that increases the rate of oxidation in the anode and the rate of reduction in the cathode. The electrically negative anode is porous to allow for the flow of hydrogen atoms. Similarly, the electrically

\footnotetext{
32 "Membrane Technology to Selectively Remove Entrapped Gases from Process," DOE Office of Industrial Technologies, Available at: https://web.archive.org/save/ embed/http://www.energy.or.kr/up load/iecenter/club00000207 energy/3-10enerfex(Membrane\%20technology).pdf
} 
positive cathode is porous, allowing for the flow of oxygen. The membrane between these electrodes is proton passive, allowing charged ions to flow through, but restricting the motion of electrons, effectively acting as an electrolyte. These characteristics make the membrane capable of conducting electricity.

As all other atoms, the hydrogen pumped to the anode is comprised of negatively charged electrons and positively charged protons. The catalyst, in conjunction with the anode, separates the hydrogen electrons from the hydrogen protons. The membrane then allows the protons to pass through while restricting the motion of the electrons. The restricted electrons flow around the membrane, thereby generating an electric current. Ultimately, the protons (passing through the membrane) and the electrons (flowing around the membrane) gather at the cathode. Oxygen present at the cathode combines with the electrons and hydrogen ions; this reaction results in the formation of a water molecule and heat. These outputs are the sole byproducts of the power generation cycle. By only emitting heat and water, PEMs eliminate significant concerns about greenhouse gasses and other emissions. Table 8 describes key characteristics of the application.

Table 8: [Appendix] Membrane Fuel Cell Summary

Applications and

Status

Recent R\&D
Commercially available

Significant amount of DOE research conducted at the Fuel Cell Technologies Office ${ }^{33}$

\subsubsection{Osmotic Power}

Osmotic power, or Pressure-retardant osmosis (PRO) uses a selectively-permeable membrane to allow a solvent, such as fresh river water, to flow into a more concentrated and pressurized solution, such as seawater. The high concentration of salt in the seawater pulls water through, to equalize concentrations across the membrane. This flow increases the pressure on the saline side, which is used by a turbine to generate power. ${ }^{34}$

Table 9 describes key characteristics of the application.

Table 9: [Appendix] Membrane Osmotic Power Summary

Applications and Status
Power generation, both centralized and distributed; currently under pilot demonstration and development; highly scalable via modular construction.

- $\quad$ Norwegian company, Statkraft, tested a prototype from 2009 to $2013^{35}$

- $\quad$ Statkraft/Hydro-Quebec joint R\&D in 2012-2013

- $\quad$ Research into thinner membranes (publication 2016) ${ }^{36}$

- $\quad$ Energy Recovery, Inc., partnership with GS Engineering and Construction Corp to advance technology and conduct pilot (2013-2014) ${ }^{37}$

\footnotetext{
${ }^{33}$ US DOE Fuel Cell Technologies Office Multi-Year Research, Development, and Demonstration Plan available at: https://energy.gov/eere/fuelcells/downloads/fuel-cell-technologies-office-multi-year-research-development-and-22

${ }^{34}$ Details available at: http://www.altenergymag.com/content.php?post_type $=2169$

35 "Osmotic Power," Presentation by Hydro-Quebec, available: http://www.hydroquebec.com/sustainable-development/documentationcenter/pdf/file-osmotic.pdf

36 "Single-atom-thick sheets efficiently extract electricity from salt water." ArsTechnica, July 2016, Available: http://arstechnica.com/science/2016/07/single-atom-thick-sheets-efficiently-extract-electricity-from-salt-water/

${ }^{37}$ Details available at Energy Recovery Inc. website: http://www.energyrecovery.com/media/osmotic-power-play-energy-recovery-teams-gsengineering-construction-corp-develop-highly-available-renewable-energy-source/
} 


\subsection{Building Envelope}

\subsubsection{Moisture Control}

Air and moisture barriers are common building envelope applications of membrane technologies. These barriers primarily seek to control air and moisture flow between conditioned and unconditioned spaces. Membranes used in air and moisture barriers are vapor permeable, like the membranes used for dehumidification described in the first section. These membranes ensure that homes and buildings are sheltered from external factors such as temperature, UV radiation, wind and water. This type of protection could be achieved with a rigid, impermeable, barrier, however, such a barrier would not allow for the transfer of water vapor. Vapor permeability is an important factor in building management as walls exposed to moisture are subject to deterioration caused by mold and rot. To address this issue, membranes allow for moisture that has found its way inside a wall to be expelled as water vapor. As such, membranes provide the perfect combination of air and water resistance and vapor permeability. Table 10 describes key characteristics of the application.

Table 10: [Appendix] Membrane Moisture Control Summary

Applications and

\section{Status}

\section{Building envelopes}

Research at US DOE and several national laboratories; e.g. Oak Ridge National Laboratory pursuing innovations in buildings including membrane enabled building envelope 38

\subsection{Appliances}

\subsubsection{Clothes Drying}

Dehumidification properties of membranes can be applied to heat recovery loops in clothes dryers to assist in the removal of excess moisture while minimizing heat loss to the environment. Table 11 describes key characteristics of the application.

Table 11: [Appendix] Membrane Clothes Dryer Summary

Applications and

Status

Recent R\&D
Clothes Dryers

Cornell University testing - Closed Loop Waste Processing Dryer

\footnotetext{
${ }^{38}$ Oak Ridge National Laboratory Innovations in Buildings http://web.ornl.gov/sci/buildings/research/envelope/
} 


\subsection{Sensors}

Membrane enabled sensors (as discussed in Section 3.2.5) are not fully commercialized but are of great interest to the sensors community. Membranes are capable of being selective of VOCs, CO, CO2, Radon, and many other potentially harmful substances that industries are interested in detecting.

Membrane-enabled sensors have the potential advantage of being highly selective and offering real time results, as compared to current sensing technologies, which often have limited selectivity and time delays in processing.

Table 12 describes key characteristics of the application.

Table 12: [Appendix] Membrane Sensors Summary

Applications and Status

Recent R\&D
- Indoor Air Quality Sensing

- Dynamic process control

Numerous research papers exist, 394041 which discuss the viability of various

membrane enabled sensors, however, there is limited data availability pertaining to companies developing such technologies

\subsection{Indoor Air Quality}

Buildings have stringent air quality requirements to ensure the health and safety of all occupants. The primary target for most IAQ applications is $\mathrm{CO}_{2}$ separations; VOC removal, however, is also a critical component of IAQ.

Adsorbents are commonly used for $\mathrm{CO}_{2}$ separations. Often, these adsorbents can be in the form of Metal Organic frameworks. Membrane based separations can also achieve removal of CO2 or other VOCs.

Related to IAQ is carbon-capture for improved outdoor air quality. This technology, currently most relevant to industrial applications can be adapted to result in improved indoor $\mathrm{CO}_{2}$ separations.

Table 13 describes key characteristics of the application.

Table 13: [Appendix] Membrane IAQ Summary

\begin{tabular}{|c|c|}
\hline $\begin{array}{l}\text { Applications and } \\
\text { Status }\end{array}$ & $\begin{array}{ll}\text { - } & \text { VOC removal } \\
\text { - } & \mathrm{CO}_{2} \text { separations } \\
\text { - } & \text { Carbon Capture }\end{array}$ \\
\hline Recent R\&D & $\begin{array}{l}\text { - Office of Science funded Carbon Capture Membrane from Lawrence Berkeley } \\
\text { National Lab } \\
\text { http://newscenter.Ibl.gov/2016/03/17/carbon-capture-membrane/ } \\
\text { - Hydrogen Selective Exfoliated Zeolite Membranes, National Energy Technology } \\
\text { Laboratory } \\
\text { https://www.netl.doe.gov/research/coal/carbon-capture/pre- } \\
\text { combustion/zeolite-membranes-min }\end{array}$ \\
\hline
\end{tabular}

\footnotetext{
${ }^{39}$ Kim et al., Synthetic Biomimetic Membranes and Their Sensor Applications; available at: www.mdpi.com/1424-8220/12/7/9530/pdf

${ }^{40}$ Barsony et al., Membrane Platforms for Sensors; available at: http://www.sciencedirect.com/science/article/pii/S1877705814024084

${ }^{41}$ Alatraktchi et al., Novel Membrane-Based Electrochemical Sensor for Real-Time Bio-Applications; available at:

https://www.ncbi.nlm.nih.gov/pmc/articles/PMC4279581/
} 


\section{Appendix B: US Department of Energy's Workshop on Separation Processes and Membrane Technologies}

June 26, 2017

\section{Stakeholder Workshop Summary - National Renewable Energy Laboratory}

\section{A.1 Summary}

On June 8, 2017, Navigant Consulting, Inc. and the National Renewable Energy Laboratory (NREL), on behalf of the U.S. Department of Energy's (DOE) Building Technologies Office (BTO), hosted a stakeholder discussion workshop to identify research and development (R\&D) needs and critical knowledge-gaps related to separation processes and membrane technologies. DOE convened this stakeholder workshop to gather input on potential research opportunities at the TRL-2 and TRL-3 stages. ${ }^{42}$ The concepts and initiative ideas gathered during this workshop will help guide a report for DOE to support research to foster advancements in membrane and separations applications.

BTO hosted the workshop at NREL. Thirty-eight stakeholders participated, including university researchers, national laboratories, manufacturers, and representatives from industry organizations. A list of attendees and their affiliations is included in the Appendix.

\section{A.2 Objective}

BTO's objective for this workshop was to gather input on where the greatest opportunities exist for both membrane and separations technologies and use this information to prepare a prioritized list of potential initiatives that can aid BTO in achieving their goals.

\footnotetext{
42 For more information on Technology Readiness Levels (TRLs), please refer to the US DOE Technology Readiness Assessment available at: https://energy.gov/sites/prod/files/em/Volume I/O SRP.pdf
} 


\section{A.3 Process and Results}

Discussions at the workshop included large-group discussions as well as smaller breakout-group sessions. Each attendee participated in two small-group discussions, with each group of participants discussing slightly differing topic-areas for the second session. During the first session, attendees:

- Discussed concepts, enabling science, and applications that can result in membrane/separation-based energy savings in building technologies.

- Developed a list of potential initiatives

Between the first and second session, stakeholders had the opportunity to engage in a round of preliminary prioritization by voting on their top-five initiatives.

The second breakout session focused on exploring, in greater detail, the top nine initiatives emerging from the preliminary-prioritization process. These discussions sought to:

- Refine initiative title and objective(s)

- Identify detailed technical challenges

- Determine most promising applications

- Identify partnership and collaboration opportunities

- Characterize desired high-level outcomes (both energy and non-energy benefits)

The first breakout session generated a total of 43 research activities (technology opportunities) for BTO to consider (hereafter "initiatives"). Participants ranked the ideas by voting on the ones that they felt were most valuable and promising for BTO to undertake. Each participant received 5 votes to distribute among the different initiatives as they saw fit (regardless of topic area).

The following table documents each proposed initiative, along with the number of votes ${ }^{43}$ it received. This table reflects the raw outputs of the workshop so items in the table may overlap or require further processing, but provide documentation of the conversations that transpired during the session

Table 1: Technology Initiatives from the First Breakout-Session

Establish building-challenge-focused targets (e.g., air quality targets) for membranes in specific applications - follow up with membrane characteristic-based targets.

Develop new materials or material processing techniques that hit cost targets, using a systems approach with interdisciplinary teams

Develop modeling tools for design of heat and mass exchangers

Develop membranes for VOC and/or $\mathrm{CO}_{2}$ removal for Indoor Air Quality (IAQ)

\footnotetext{
${ }^{43}$ The total number of votes does not equal 5 votes/person multiplied by 39 attendees because: 1) Some attendees departed prior to
} voting; 2 ) the workshop facilitators did not vote. 


\section{Initiative}

Standardized test-method development for membranes, including mass transfer metrics and mechanical properties

Develop multi-functional membranes that work in many applications

Systems understanding top-down analysis to inform research and leverage multifunctionality

Develop self-healing membranes

Development of hybrid membranes (not just all organic/polymeric)

Solar-based dehumidification for buildings (enabled by metal-organic frameworks treated as an adsorbent)

Optimize membrane methods/properties for improved bonding

Metal-organic frameworks (MOFs) for advanced control of chemical properties

Membranes for clean-water extraction during waste-water treatment

Develop membranes that allow for high flux

Membrane-based heat/energy storage for daily/seasonal cycles

Support further development of absorption heat pumps

Develop thinner materials that can withstand higher pressure gradients

Conduct longevity studies of membrane-based systems

Develop cost-effective manufacturing processes for creating drop-in membrane modules (easy to assemble)

Develop new, less-energetic separation technologies

Membrane-enabled cooling towers using seawater (that manage scale build-up)

Develop membrane-based low-cost sensors that discriminate between different pollutants/gases

Support development of improved durability and reduced fan-power-loss for membranes for latent-heat removal

Develop low-power, long-life sorption/desorption for indoor air quality sensing 
Initiative

Evaluate opportunities for improving membrane strength and durability

In situ membranes grown directly on a porous support (for mechanical integrity only)

Develop membranes to minimize thermal losses in buildings 2

Develop error-proof vapor-permeable envelope air-barriers 2

Develop membrane-enabled design guide 2

Water selectivity for high-permeance membranes (at high RH) 2

Development of leak-proof hollow-fiber membranes 1

Develop membranes to handle more varied permeates (particularly vacuum 1 permeate)

Incorporation of biologics (robust geometries/materials in nature and integrate them)

Develop integrated 2-phase materials (e.g. materials with one phase supporting structure and another supporting transport)

Develop membrane-based VOC sensors 1

Testing for scale-up of membrane applications. $\quad 1$

Minimize pressure drops in filtration processes 1

Identify and develop low-cost sensors for dynamic process control 0

Membrane moisture-recovery in polluted airstreams (lab vent-hoods) 0

\section{A.4 Next Steps}

Navigant, in conjunction with BTO, will continue to refine and develop these initiatives though additional research and follow-up interviews with individual stakeholders who were unable to attend the workshop. Navigant will produce a report that recommends to DOE the initiatives to consider pursuing, based on some or all the following criteria:

- Fit with BTO mission

- Criticality of DOE involvement

- Impact

- Time to impact

- Stakeholder input (including voting results) 
DOE will consider the recommended outputs of these prioritization processes for funding in parallel with other priorities in other building end-use areas. Therefore, no recommended output from this opportunity assessment is guaranteed to receive DOE support.

The workshop outputs, incorporated into Navigant's future report, will serve as a guide for DOE and its partners to increase support of membrane and separation technologies while maintaining the competitiveness of American industry. 


\section{A.5 Workshop Attendees}

Navigant and DOE wish to thank all the workshop participants. The suggestions, insights, and feedback provided during the workshop are critically important to identifying and prioritizing membrane and separations initiatives.

The stakeholder discussion workshop brought together 39 individuals representing a range of organizations across the industry. Table 2 lists all the attendees and their affiliations.

Table 2: Stakeholder Workshop Attendee List

\begin{tabular}{|c|c|}
\hline Attendee Name & Organization \\
\hline Omar Abdelaziz & Oak Ridge National Laboratory \\
\hline Bamdad Bahar & Xergy Inc. \\
\hline Steven Baker & Emerson Climate \\
\hline Youssef Bargach & Navigant Consulting, Inc. \\
\hline Daniel Betts & Be Power Tech, Inc. \\
\hline Uwe Beuscher & WL Gore \& Associates \\
\hline Brian Bischoff & Oak Ridge National Laboratory \\
\hline Antonio Bouza & US Department of Energy \\
\hline Mark Buelow & BASF \\
\hline Frederick Cogswell & United Technologies Research Center \\
\hline Panos Datskos & Oak Ridge National Laboratory \\
\hline Steven C. DeCaluwe & Colorado School of Mines \\
\hline Jason DeGraw & National Renewable Energy Laboratory \\
\hline Debra Deininger & Integrated Device Technology \\
\hline Chaiwat Engtrakul & National Renewable Energy Laboratory \\
\hline Michael Geocaris & US Department of Energy \\
\hline Bill Goetzler & Navigant Consulting, Inc. \\
\hline Matt Guernsey & Navigant Consulting, Inc. \\
\hline Chioke Harris & National Renewable Energy Laboratory \\
\hline Michael Hu & Oak Ridge National Laboratory \\
\hline Ryan Huizing & dPoint Technologies \\
\hline Roderick Jackson & Oak Ridge National Laboratory \\
\hline Brian Johnson & Dais Analytic Corporation \\
\hline Eric Kozubal & National Renewable Energy Laboratory \\
\hline Chuck Kutscher & National Renewable Energy Laboratory \\
\hline Jason Lustbader & National Renewable Energy Laboratory \\
\hline Peter Luttik & 7AC Technologies \\
\hline Jeffrey McCutcheon & University of Connecticut \\
\hline Saeed Moghaddam & University of Florida \\
\hline Sven Mumme & US Department of Energy \\
\hline John Pellegrino & University of Colorado \\
\hline Jim Peters & PPG Industries \\
\hline Sameer Rao & Massachusetts Institute of Technology \\
\hline Rob Tenent & National Renewable Energy Laboratory \\
\hline
\end{tabular}




\begin{tabular}{ll}
\hline Attendee Name & Organization \\
\hline Ed Trudeau & Emerson Climate \\
Jeffrey Urban & Lawrence Berkeley National Laboratory \\
Michael Wofsey & US Department of Energy \\
Jason Woods & National Renewable Energy Laboratory \\
John Zhai & University of Colorado \\
\hline
\end{tabular}




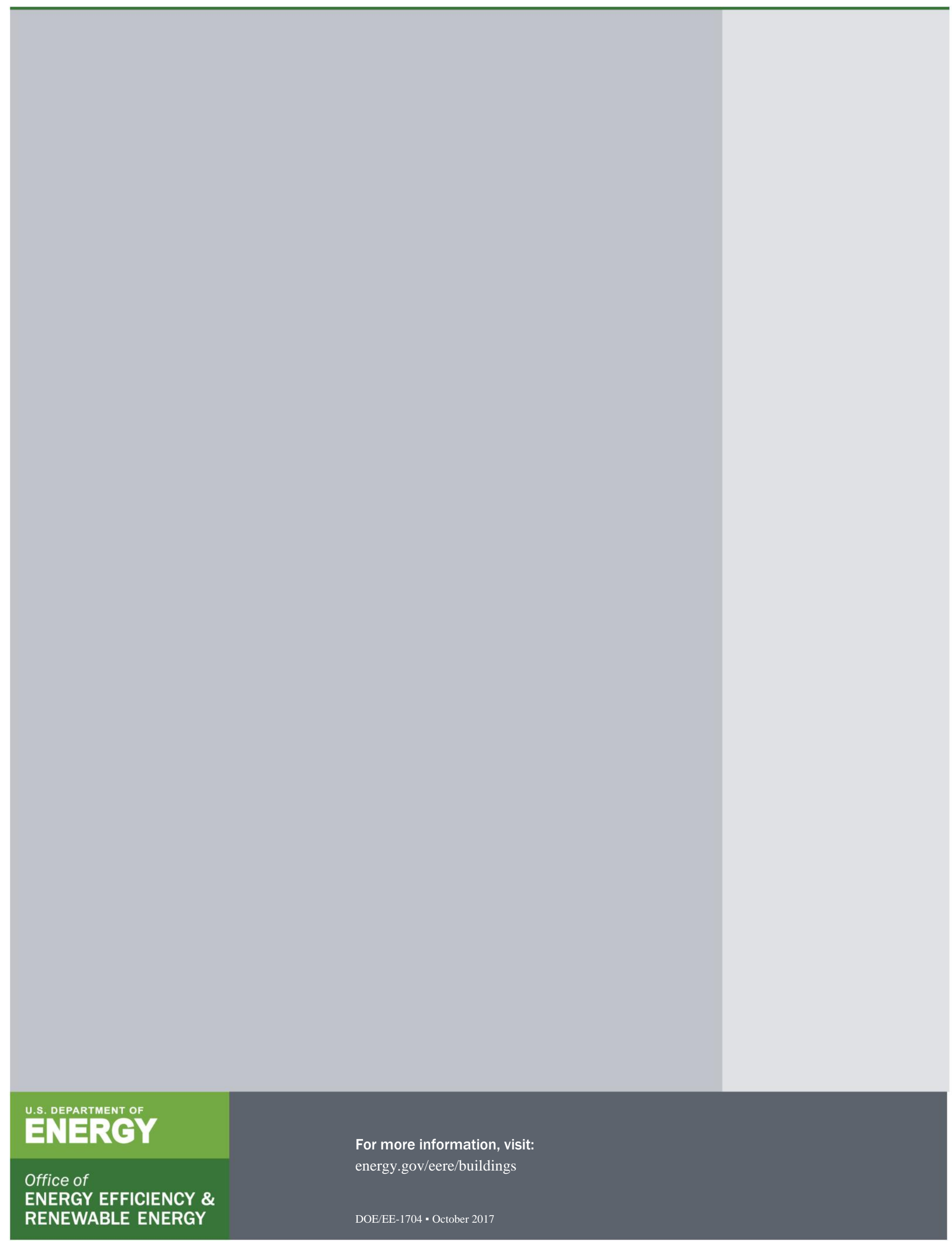

